\title{
Drag reduction methods at solid-liquid interfaces
}

\author{
Min LIU, Liran MA* \\ State Key Laboratory of Tribology, Tsinghua University, Beijing 100084, China \\ Received: 03 August 2020 / Revised: 05 January 2021 / Accepted: 14 February 2021 \\ (C) The author(s) 2021.
}

\begin{abstract}
Friction drag is a nonnegligible matter when relative motion happens between solid and liquid phase, which brings many inconveniences in ship navigation, fluid transportation, microfluid devices, etc. Thereby various methods have been developed focusing on friction drag reduction. In this article, a review of several widely studied drag reduction methods is given, specially, their advantages and limitations in practical applications are discussed. Besides, a comparison of different methods is made and the development prospect of drag reduction is concluded.
\end{abstract}

Keywords: drag reduction; microstructures; superhydrophobic surfaces; supercavitation; polymer additives

\section{Introduction}

Solid-liquid interfaces are ubiquitous in nature, while friction drag always comes along when relative motion happens between solid and liquid phase, such as marine navigation, pipeline transportation, microfluid device operation, etc. According to the reports, marine shipping alone accounts for about $12 \%$ of world's transportation energy consumption, where friction drag is verified to contribute to $60 \%-80 \%$ of the total drag on vessels $[1,2]$. That means drag reduction at the solid-liquid interfaces would have a significant influence on performance promotion of underwater vehicles and energy saving, which makes it an invariant hot spot in recent decades [3-8].

Consequently, solid-liquid drag reduction has been extensively studied, and a range of methods have been developed, including surface microstructures [9-13], superhydrophobic surfaces [14-16], supercavitation [17-20], microbubbles [21-27], polymer additives [28-31], oscillating wall [32-38], and compliant wall [39-45]. Moreover, a new technique named superlubricity, defined as the state of friction coefficient in the order of 0.001 or lower, has made the solidliquid interface drag reduction usher in a new dawn.
For instance, in shipping industry, superlubricity can be applied both in engine cylinders and hull surfaces to reduce component friction and sailing resistance, thus lower the energy consumption dramatically [46]. And its suitability for a wide range of applications is so attractive that a new time called "superlubricitive engineering" is predicted to be coming soon, where we may be able to get rid of friction drag and energy consumption permanently [46-55].

In this article, although most of these drag reduction methods have been proved effective or shown enormous economic benefits in some cases, it is not possible to give a throughout introduction of all these methods in this short review. Hence, on the consideration of their development status and own features, here we choose four of the most representative and promising drag reduction methods for detailed description, namely, surface microstructures, superhydrophobic surfaces, supercavitation, and polymer additives. Then a comparison of all these methods mentioned above is made according to the reported results. Furthermore, a discussion on the development direction and prospect of solid-liquid interface drag reduction is drawn out, in an attempt to bring the readers a better insight into this issue.

* Corresponding author: Liran MA, E-mail: maliran@tsinghua.edu.cn 


\section{Drag reduction by microstructures}

People may easily accept the idea that the smoother the surface, the smaller the friction is, but the observation of fast-moving creatures like swordfish and sharks exhibits a surprising result that they all have rough surfaces with special microstructures on their skin (see Fig. 1) [56-59]. These findings bring new inspiration to friction drag reduction, and further research through experiments and numerical simulations concerning the patterns, distribution, geometric parameters, and mechanism of microstructures emerged in large numbers.

Among the relevant researches, the study of biomimetic riblet microstructures imitating the three-dimensional interlocking shield scale groove structures of shark skin is more in-depth [10-13]. Walsh and Weinstein [60] were the first to conduct an investigation regarding the drag characteristics of longitudinally ribbed surfaces in 1978, and a small drag reduction less than $4 \%$ was obtained with two of the triangular grooved models. Further they examined the influence of height and spacing of typical V-shaped riblets by systematic experiments, which indicated that a maximum drag reduction of $7 \%-8 \%$ could be obtained for $h^{+}=13$ and $s^{+}=15$, where $h^{+}$and $s^{+}$ are height and spacing of riblets in law-of-the-wall variables defined as:

$$
\begin{aligned}
& h^{+}=\left(h U_{\infty} / v\right) \sqrt{c_{\mathrm{f}} / 2} \\
& s^{+}=\left(s U_{\infty} / v\right) \sqrt{c_{\mathrm{f}} / 2}
\end{aligned}
$$

where $h$ is the riblet height, $s$ the riblet spacing, $U_{\infty}$ the free-stream velocity, $v$ the kinematic viscosity,

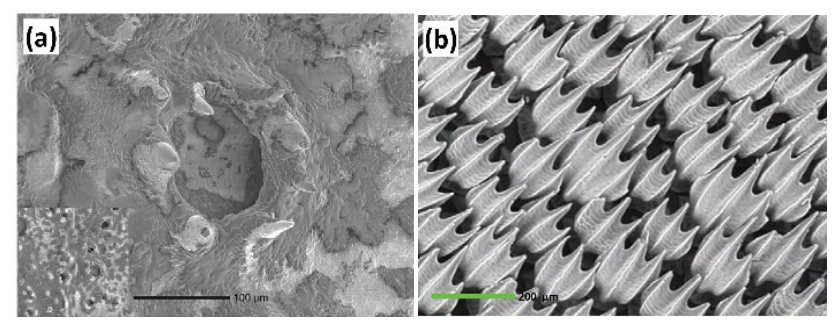

Fig. 1 Images of swordfish and shark skin surface: (a) Pores and denticles on the swordfish head. Reproduced with permission from Ref. [58], (C) The Company of Biologists Ltd., 2016. (b) Riblets on the shark anal fin. Reproduced with permission from Ref. [59], (C) The Company of Biologists Ltd., 2014. and $c_{\mathrm{f}}$ the local skin friction [61]. In addition, more studies have been constantly conducted to verify the relationship between friction drag and design parameters, including the size and shape of microstructures $[62,63]$. Generally, the size of riblets is in the range of $50-500 \mu \mathrm{m}$ and the shape can be blade-like, V-shaped (or called triangular), T-shaped, etc. [64, 65]. Despite the influence of various implementation conditions, it is suggested that there are some design rules in common. For instance, the drag reduction rate is proportional to the riblet size for small riblets, and the optimal riblets spacing may existence in the range of $10<s^{+}<20[65,66]$. But more effective prediction methods still need to be developed.

After the early research of Walsh and Weinstein, Bechert et al. [67] carried out a study on fast sharks, observed the morphology of shark scales, and explored the mechanism of drag reduction. In 1994, Park and Wallace [68] made detailed measurements of a riblet groove surface, and revealed that a drag reduction rate of $4 \%$ was obtained and the riblet valleys can reduce the vertical flux of streamwise momentum significantly. After that, a considerable improvement over skinfriction reduction was found by Bechert et al. [62], by a systematic experimental optimization with the utilization of an oil channel, a drag reduction rate as high as 9.9\% was proved to be possible for a surface with ribs and/or slits. Apart from the 2D-riblets, experiments on 3D-riblet surfaces was also launched by Bechert et al. [13], but the best performance of 3D-riblets was still about $1.7 \%$ lower compare with $2 \mathrm{D}$-riblets. Delightedly, shark-skin like microstructures were applied to swimsuits successfully and left a quite impressive performance in the 2000 Sydney Olympic Games. Besides, there is a critical Reynolds number which determines whether drag reduction can occur, and Quintavalla et al. [69] demonstrated that the changing of groove shape, width, or depth which influence the total groove area could have a notable effect on the critical Reynolds number. In recent years, numerical simulation is more frequently used in analyzing the drag reduction behavior of surface microstructures, such as the investigation conducted by Daeian et al. [70] using the Shan-Chen lattice Boltzmann multi-phase model, as shown in Fig. 2, which revealed the effect of the groove parameters on 


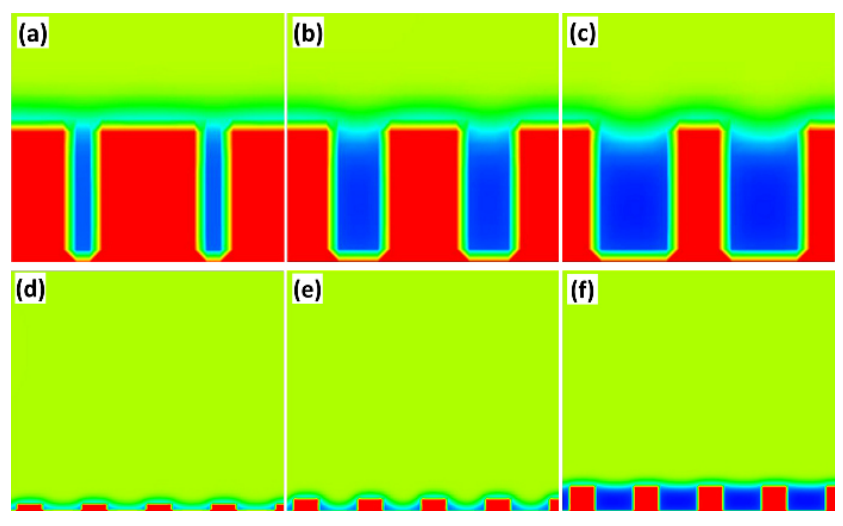

Fig. 2 Comparison of the meniscus shape for different groove parameter values: $(a-c)$ Different groove width. $(d-f)$ Different groove height (the red area represents the grooves). Reproduced with permission from Ref. [70], C IOP Publishing, 2017.

the drag reduction performance in a 2D parallel-plate channel with microstructures. Another example is the numerical simulations carried out by Lee et al. [71], which predicted the motion path of contaminants on 3D sharklet-patterned surfaces under perpendicular flow and parallel flow, as shown in Fig. 3, and indicated that the flow characteristic is a critical factor that influence the performance of biomimetic patterned surfaces.

In this part, we will introduce the fabrication methods of surface microstructures in detail, and summarize the proposed theories of drag reduction mechanism.

\subsection{Fabrication methods of microstructures}

Scientists developed various methods to effectively obtain the sharkskin-like surfaces with prepared microstructures. Here we divide the common methods into three categories and introduce them respectively.

\subsubsection{Replicated forming method}

The replicated forming method refers to a preparation

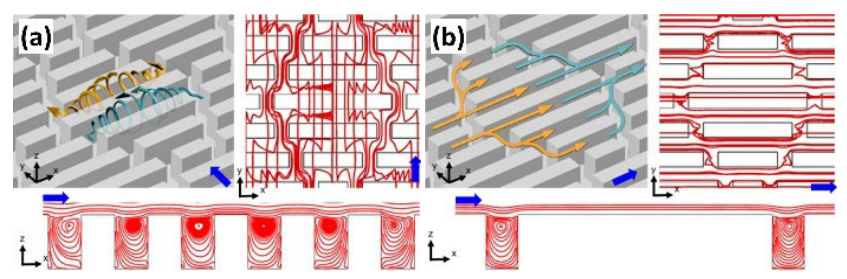

Fig. 3 Simulation of sharklet-patterned surfaces under: (a) Perpendicular flow. (b) Parallel flow. Reproduced with permission from Ref. [71], (C) Elsevier, 2020. process that first replicates the original microstructure surface to obtain a template, then pours soft materials or plastic fluid into the template or just prints to obtain the required surface microstructures, as the example shown in Fig. 4 [10, 72].

Typically, it is an effective way to fabricate precise biomimetic surfaces, and following this basic principle, specific techniques such as micro-molding, microembossing, vacuum casting replication, elastomeric stamping, and electrocasting are further developed $[10,73]$, thus extending the application range of replicated forming. However, the increased costs with the improvement of accuracy limit its large-scale application. And for this issue, it is suggested that the inducing of rolling and grinding process may provide a promising way for solving this problem.

\subsubsection{Etching method}

Etching method is a way to achieve the fabrication of surface microstructures by removing part of materials from substrate in a designed pattern, specifically including laser etching, photolithography, electronbeam lithography, plasma etching, chemical etching, and so on, as shown in Fig. 5 [74-77].

From Fig. 5 we can see clearly that while all the listed etching methods can create the grooves by removing a thin material layer selectively, there is an obvious difference in manufacturing accuracy. But we should notice that even laser etching has a lower accuracy because of the ablation and melting of matrix [78], it is one of the most widely used methods since it is fully developed, which significantly improves the manufacturing processes of riblets [79].

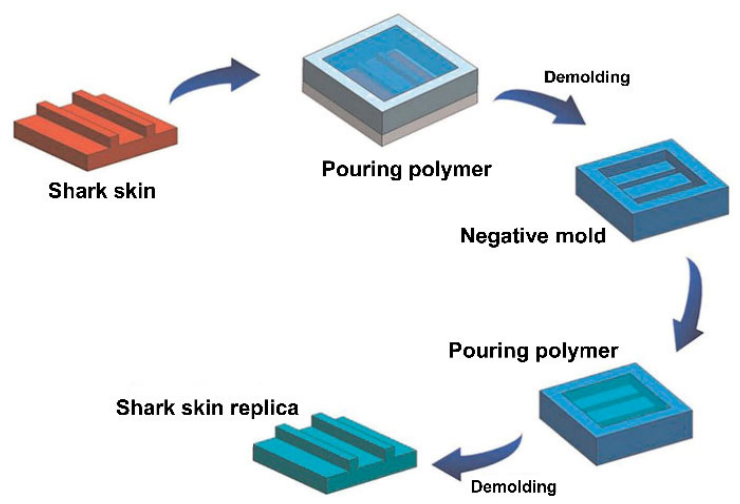

Fig. 4 Schematic diagram of the replicated process of a shark skin surface. Reproduced with permission from Ref. [10], (C) John Wiley \& Sons, 2016. 

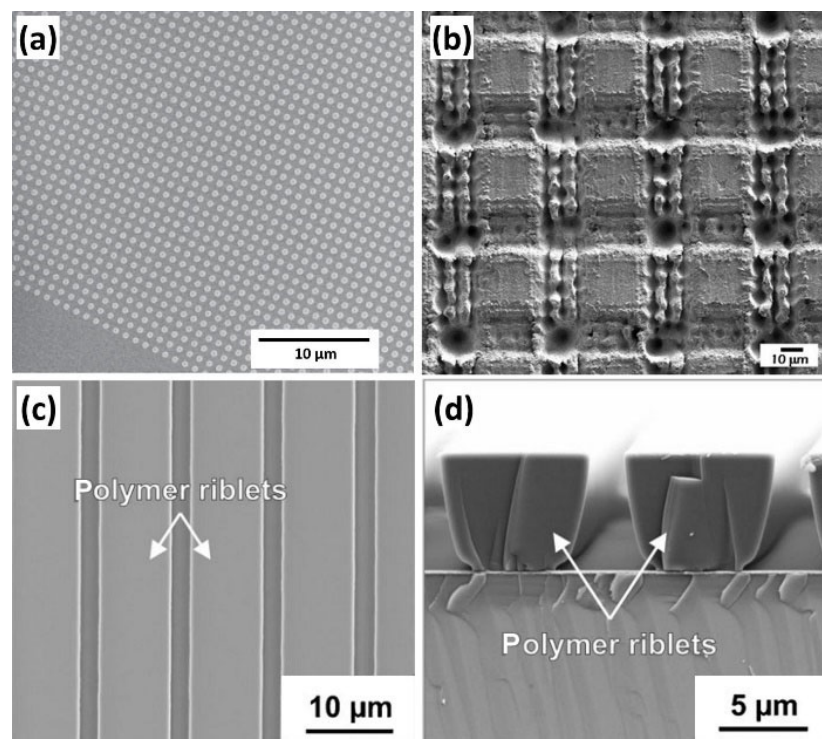

Fig. 5 Microstructures fabricated by different etching methods: (a) Nanopillar array fabricated using electron-beam lithography. Reproduced with permission from Ref. [76], C) Springer Nature BV, 2007. (b) Matrix micropattern fabricated by laser. Reproduced with permission from Ref. [75], (C) Elsevier, 2016. (c) Top view and (d) cross section of polymer structures fabricated by photolithography. Reproduced with permission from Ref. [77], (C) John Wiley \& Sons, 2011.

Another point should be noted is the limitation of these methods in the fabrication of complex 3D microstructures, as they are more suitable for the preparation of simple solid geometric patterns. That means for etching methods there is still a long way to go to meet the demands of practical production.

\subsubsection{Additive manufacturing}

Additive manufacturing, also known as 3D printing, is a newly developed manufacturing process, with an outstanding advantage that highly complex customized structures could be fully fashioned.

To date, additive manufacturing has attracted the interests of many scholars, and recently, new methods based on 3D printing have been developed to adapt to the fabrication of surface microstructures, and shark-skin like structures have been created by $3 \mathrm{D}$ printing successfully. As shown in Fig. 6, Li et al. [80] developed a multiscale stereolithography technology based on 3D printing to prepare shark-skin like micro features in a pipe, which demonstrated an excellent drag reduction function of nearly $10 \%$. Another noticeable work was carried out by Wen et al. [59], that a flexible biomimetic shark skin with thousands of rigid shark denticles was fabricated by constructing 3D model of denticles and printing on flexible membranes in a controlled, linear-arrayed pattern (see Fig. 7), and an increase in swimming speed was observed under certain motion programs while the energy consumption decreased.

Overall, recent years have witnessed a substantial progress in the fabrication of biomimetic surface microstructures, and the continuously induce of other technologies like electrostatic spinning, self-assembly, sol-gel method, or electroless plating [81, 82] enriched the choices to choose from. However, it is still fairly difficult to meet the actual requirements of low cost, large-scale production. New approaches considering the cost, precision, and mass production need to be further developed, and much effort should be exerted in this respect.

\subsection{The mechanism of surface microstructure drag reduction}

Results show that vortices generate in turbulent flows while animals or objects move fast in the fluid, which causes an increase in resistance. But the phenomenon that the shear stress of a riblet surface is lower than that on a smooth surface initiated the

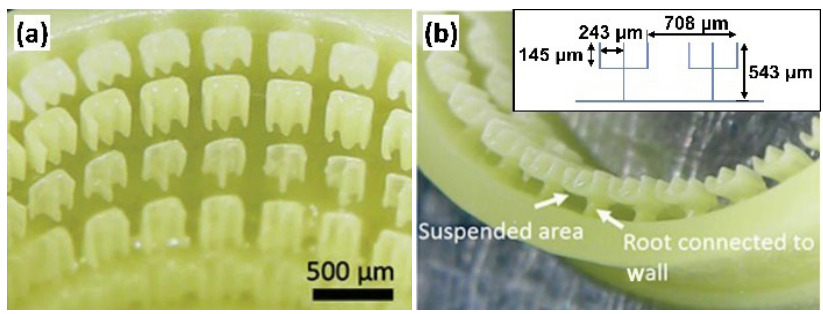

Fig. 6 3D printed pipe with artificial shark skin microstructures: (a) Top view. (b) Side view. Reproduced with permission from Ref. [80], (C) John Wiley \& Sons, 2019.

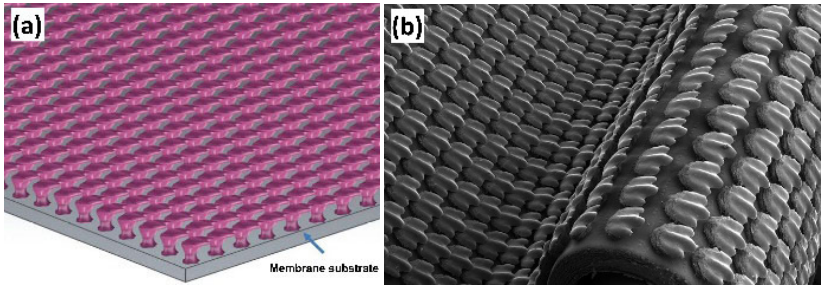

Fig. 7 3D printed flexible biomimetic shark skin: (a) Threedimensional model of shark skin denticles. (b) Fabricated shark skin in a curved state. Reproduced with permission from Ref. [59], (C) The Company of Biologists Ltd., 2014. 
concerns of scholars, and a variety of theories on the mechanism of microstructure drag reduction have been put forward.

The protruding height theory proposed by Bechert et al. $[13,62,83]$ emphasizes that a protrusion height difference exists between the longitudinal and cross flow origins, thus the pinning of riblets to cross flow and the limitation of grooves on momentum transfer degree result in a wall shear stress reduction. On the other hand, Bixler and Bhushan [9, 84] concluded that the anisotropic flow encouraged by riblets and the lifting and pinning of vortices in near wall boundarylayer are the reasons for a lower friction. And according to the direct numerical simulation conducted by Choi et al. [10, 85], the mechanism of drag reduction is that the micro spacings of riblets can restrict the areas exposed to high-speed fluid, such that the viscous drag is reduced, as illustrated in Fig. 8.

Of course other opinions, such as the assumption that the existence of vortices in the riblet valleys functions as antifriction bearing (see Fig. 9) and consequently scales down the friction drag [86], or the decrease of viscous drag can occur on the slope surface because of the back-flowing phenomenon, are also supported by some experiments.

The above are some representative theories to explain the mechanism of surface microstructure drag

(a)

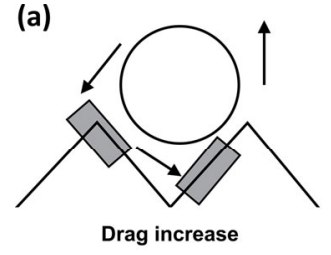

High skin-friction region due to downwash motion

Fig. 8 Schematic diagram of: (a) Drag increase and (b) drag reduction mechanisms by riblets. Reproduced with permission from Ref. [10], (c) John Wiley \& Sons, 2016.

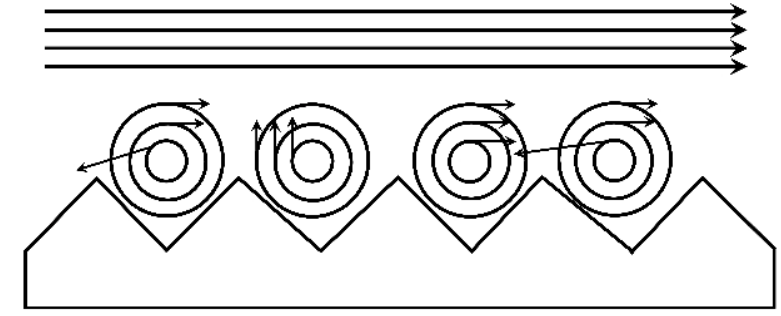

Fig. 9 Schematic diagram of the drag reduction mechanism of spanwise riblets. Reproduced with permission from Ref. [86], (C) The authors, 2017. reduction, but so far, there is no final conclusion, and we are looking forward to seeing that a more complete theory could be brought up.

\subsection{Summary}

Studies about microstructure drag reduction have been carried out in these decades, and many achievements have been completed. However, the mechanism is still uncertain and needs more verification. Furthermore, it is self-evident that the large-scale application of microstructure drag reduction is of great importance. One of the main barriers in this field is the manufacture of high-precision large-scale biomimetic surface microstructures at low cost. New technologies are expecting to be introduced into microstructure manufacturing process and thus improving the precision of bionic production. Another problem is that even experiments have been performed in the laboratory successfully, they are difficult to be applied in practice because of the complexity of the real environments, therefore, relevant solutions for industry applications need to be further studied.

\section{Drag reduction by superhydrophobic surfaces}

Superhydrophobic is a state that the contact angle between the surface and the water drop is higher than $150^{\circ}$ [16]. It was discovered in the very beginning of the 20th century, but had experienced a relatively cold situation before the mid-1990s, right until the thorough explanation of "lotus effect" by Neinhuis and Barthlott $[87,88]$ in 1997. Since then, observations of superhydrophobic phenomenon in nature have attracted widespread attention. Inspired by special patterned surfaces obtained from plant leaves, animal feathers, and insects, various kinds of superhydrophobic surfaces with special micro-/nanostructures have been prepared, and different functions such as self-cleaning [89], anti-biofouling [90], anti-icing [91, 92], and oil-water separating [93] have been constantly discovered and applied. And with the continuing advance of superhydrophobic surfaces, their applications in fluidic drag reduction arouse the great interests of researchers.

It can be generally concluded that the research on superhydrophobic surface drag reduction has gradually 
developed from laminar drag reduction to turbulent drag reduction. As early as 1999, Watanabe et al. [94] had reported that superhydrophobic coatings can be applied to laminar flow drag reduction for Newtonian fluids.

Then in 2004, Ou et al. [95] found a reduction up to $40 \%$ by measuring the pressure drop when laminar flow of water passed through microchannels with hydrophobic surfaces, which demonstrated significant drag reduction. Later, Joseph et al. [96] verified the existence of slippage when water flowed through superhydrophobic carbon nanotube forests inside the microchannels in 2006, while Choi et al. [97] successfully measured the slip length of water $(20 \mu \mathrm{m})$ and $30 \mathrm{wt} \%$ glycerin $(\sim 50 \mu \mathrm{m})$ flowing through nanostructured superhydrophobic surface, which further proved the effectiveness of superhydrophobic surfaces in laminar flow drag reduction.

After this, as turbulent boundary layer flows representing the main applications, the possibility of superhydrophobic surface drag reduction in turbulent flow turned into the next concern [98-100]. In 2009, Daniello et al. [7] confirmed the feasibility of superhydrophobic surfaces in turbulent drag reduction, and a drag reduction approaching 50\% was measured. In 2014, Bidkar et al. [8] further presented watertunnel test data that showed sustained drag reduction ability, and provided evidences that to maintain the drag reduction effect for a long period in turbulent flow regimes, a low level of surface roughness, the formation of a Cassie state, and the ability of retaining trapped air are all required. In the same year, Park et al. [98] achieved a drag reduction rate as large as $\sim 75 \%$, which positively confirmed that superhydrophobic surfaces can obtain excellent drag reduction effect in turbulent flows.

So far, superhydrophobic drag reduction has been proved to be effective both in laminar flows and turbulent flows, and significate drag reduction rates could be obtained through proper operation. However, while big progress has been achieved in this area, there are still some key problems waiting to be solved in the practical application, which also become the focus of research in recent years. In this part, first we will introduce the preparation principle, methods, and the drag reduction mechanism of superhydrophobic

surfaces, then give a discussion about the key problem in implementation.

\subsection{Preparation principle and methods of super- hydrophobic surface}

The hydrophobic and hydrophilic properties of surfaces are usually characterized by contact angle, which is related to surface free energy. Young's equation, as shown in Eq. (3), was the first theoretical expression to describe it specifically.

$$
\cos \theta=\left(\gamma_{\mathrm{sv}}-\gamma_{\mathrm{sl}}\right) / \gamma_{\mathrm{lv}}
$$

where $\theta$ is the contact angle under equilibrium condition, $\gamma_{\mathrm{sv}}$ is the surface tension of solid surface under saturated vapor, $\gamma_{\mathrm{sl}}$ is the interfacial tension between solid and liquid, and $\gamma_{\mathrm{lv}}$ is the surface tension of liquid under its own saturated vapor pressure. It is generally considered that the surface of the material is hydrophobic when $\theta>90^{\circ}$ and hydrophilic when $\theta<90^{\circ}$.

On this basis, two further developed models called Wenzel model and Cassie-Baxter model, as shown in Fig. 10, were proposed by Wenzel and Cassie-Baxter respectively to describe rough surfaces [101-103]. And the liquid on the superhydrophobic surfaces can thereby be divided into Wenzel state and CassieBaxter state, which has an important influence on the surface properties: the surfaces dominate by CassieBaxter state show low adhesion and self-cleaning property such as lotus leaves [88], and for Wenzel state, high adhesive forces for water can be found, such as red rose petal [104, 105].

Detailed analyses focusing on the surface roughness were carried out based on these two models, and the results show that whether the contact mode is Wenzel or Cassie-Baxter state, high surface roughness will increase the hydrophobicity of hydrophobic surfaces

(a)

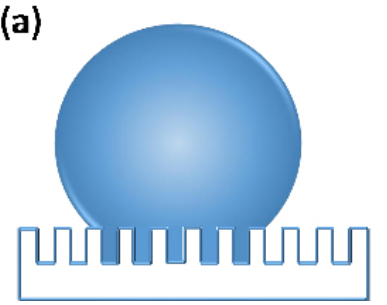

Fig. 10 Sketch of water drops on rough surface: (a) Wenzel state; (b) Cassie-Baxter state. (b)

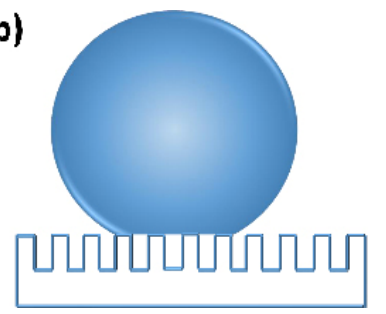


or hydrophilicity of hydrophilic surfaces in the same measure. Consequently, the preparation of superhydrophobic surfaces can be realized by constructing micro-/nanostructures. In addition, it is worth noting that a superhydrophobic surface was fabricated by the preparation of columnar microstructure on hydrophilic surface by Wang et al. [106], which provided a new way to achieve superhydrophobicity.

To obtain superhydrophobic surfaces, methods developed can be divided into three ways according to different principles. The first one is to construct microstructures on the low surface energy substrates [107], the second one is to modify the rough surfaces with low surface energy materials [108], and the third one is to spray coatings containing nanoparticles and low surface energy materials on the substrates [109, 110]. It has been pointed out that surface microstructure is the main factor determining the superhydrophobic properties rather than low surface energy materials, as it's hard to achieve superhydrophobicity only by changing the surface free energy. Since we have introduced the microstructure constructing methods in Section 2.1, they are not listed here again.

\subsection{The mechanism of superhydrophobic surface drag reduction}

It can be seen from the above discussion that the realization of superhydrophobic surface drag reduction largely depends on the design of surface microstructures, therefore, some scholars explain the mechanism from this aspect. But for more researchers, the water repellency and trapped air in the microstructures are the main reason for drag reduction effect of superhydrophobic surfaces, as a new air-liquid boundary condition can be established [15, 111-113]. To further confirm the function mechanism, both experiments and numerical simulations are widely used in the analyses, and the results indicate that the decrease in shear resistance is attribute to the velocity slip at the interface $[109,114]$, as illustrated in Fig. 11 [15, 115, 116].

Mathematical expressions and explanations are also developed according to this theory. A typical example is the expressions carried out by Choi and $\operatorname{Kim}[97,112]$ to calculate the drag reduction (DR) in Couette flow and Poiseuille flow using $b_{\text {slip }}$ and $h$, as described in

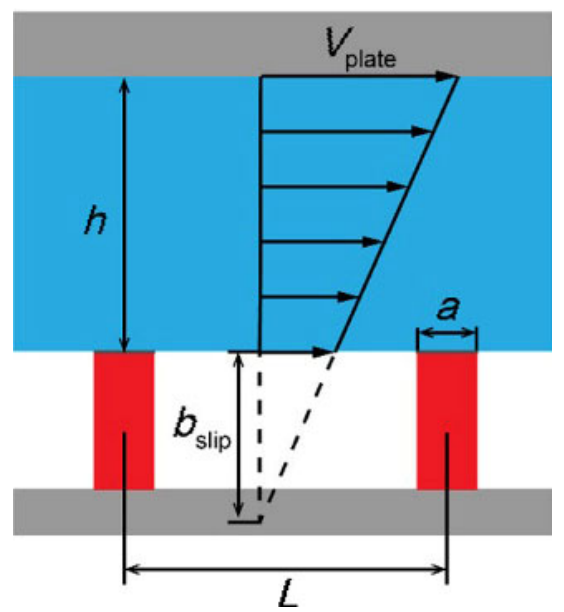

Fig. 11 Schematic diagram of the laminar flow over a patterned surface. $b_{\text {slip }}$ is the slip length, $h$ is the laminar flow thickness, $V_{\text {plate }}$ is the velocity of the plate, $a$ is the width of the groove, $L$ is the length between two grooves. Reproduced with permission from Ref. [116], (c) American Chemical Society, 2020.

Eq. (4) and Eq. (5), respectively.

$$
\begin{aligned}
& \mathrm{DR}=1 /\left(1+\frac{h}{b_{\text {slip }}}\right) \\
& \mathrm{DR}=3 /\left(3+\frac{h}{b_{\text {slip }}}\right)
\end{aligned}
$$

Dong et al. [117] gave an explanation using the hypothesis in Newton's law of viscosity for this slip boundary theory, as shown in Eq. (6).

$$
F=\mu A \frac{\mathrm{d} u}{\mathrm{~d} y}
$$

where $F$ is the drag force, $\mu$ is the dynamic viscosity of the fluid, $A$ is the wetting area, and $\mathrm{d} u / \mathrm{d} y$ is the velocity gradient in the fluid. They stated that despite the small impact of wetting area, and taking $\mu$ as a constant, the value of $F$ is only related to $\mathrm{d} u / \mathrm{d} y$, which means the trapped air on the superhydrophobic surface conduces to a slippage on boundary layer, and the value of $\mathrm{d} u / \mathrm{d} y$ is then reduced, finally results in the decrease in drag force.

\subsection{A key problem in the application of super- hydrophobic surfaces}

These years, as sustained progress has been made in laboratory research, scientists are paying more 
attention to the applications of superhydrophobic surfaces, and long-term durability of superhydrophobic surfaces has become a critical problem in practical implementations.

Generally, there are two main aspects that affect the longevity of superhydrophobic surface drag reduction. First, it is the constancy of plastron in high-pressure and high-speed flows. A large number of studies have shown that the frangibility of the thin air layer has been the main reason for drag reduction efficiency change with time, especially in large facilities and turbulent flows in actual environment, and the replenishment of the diffused plastron with air was proved effective in maintaining long-term drag reduction [98, 116, 118, 119]. Guided by this principle, associated methods such as thermal, pneumatic, electrolytic, and chemical methods have been developed [120]. One typical work was carried out by Lee and Kim [120], that they devised a electrolytic method to replenish gas automatically at the air loss positions using thin-film gold cathode on the substrate surface and copper anode in the water. Similarly, Panchanathan et al. [121] demonstrated a chemical method to produce gas at the points of liquid infiltration by the catalytic decomposition of hydrogen peroxide, as depicted in Fig. 12.

The second influence factor is the mechanical strength of surface microstructures. For this problem, Cheng et al. [110] proved that the drag-reducing

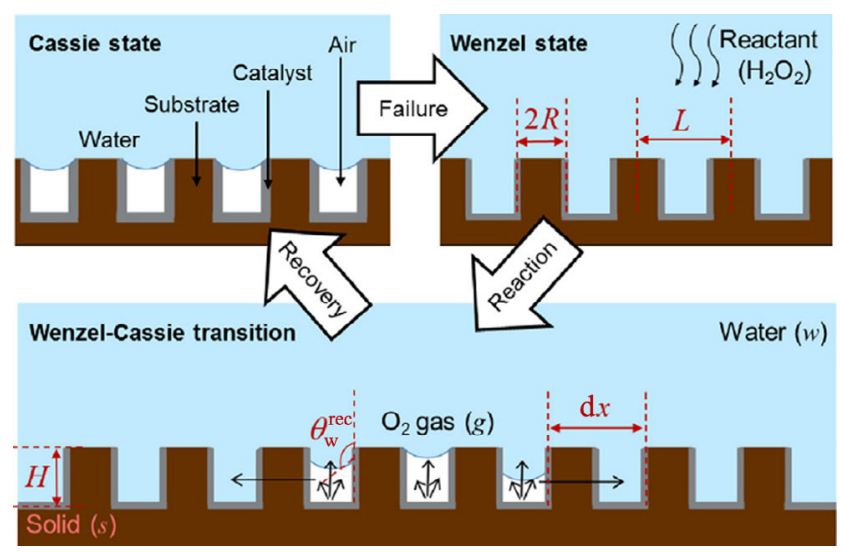

Fig. 12 Sketch of an active superhydrophobic microtexture that generates gas on-demand upon addition of the reactant, hydrogen peroxide. $H, 2 R, L$ is the texture height, width, pitch respectively, $\theta_{\mathrm{w}}^{\mathrm{rec}}$ is the contact angle of plastron recovery, $\mathrm{d} x$ is width of the small area where gas front displaces water. Reproduced with permission from Ref. [121], (C) American Chemical Society, 2018. property could be prolonged by enhancing the mechanical stableness of superhydrophobic surfaces, including the immobilization of rough structures, and the regulation of surface energy and the coating's elastic property. Most recently, Wang et al. [14] constructed a superhydrophobic surface with armourlike interconnected frame microstructure to provide protection for highly water-repellent but fragile nanostructures, as shown in Fig. 13, which offers a new idea for long-term superhydrophobic drag reduction.

On the basis of these studies, experiments in practical environments have been also gradually conducted, but the diverse results seem not so satisfactory as expected [6, 122]. Happily, in 2020, significant drag reductions of $30 \%-40 \%$ were obtained in the experiments conducted with an approximately 4-m-long boat in open water by $\mathrm{Xu}$ et al. [6], which confirmed the drag-reducing capacities of superhydrophobic surfaces in turbulent flows of practical interest.

\subsection{Summary}

Superhydrophobic surface drag reduction is a simple, effective method with an excellent performance. It is widely studied since it's of avail in both laminar and turbulent flow and has a broad application prospect. However, the main issue of this method in practical application is the instability of plastron in high-pressure or high-speed fluid and poor mechanical durability of microstructures [98, 110, 116, 118, 119, 123]. Furthermore, porous structures formed in the superhydrophobic layer decrease its corrosion resistance, and in seawater creature fouling always does great damage to its surface morphology constantly until the surface loses drag reduction ability. Therefore, the specific mechanism of superhydrophobic surfaces, and their long-term application in large objects in a variety of real environments need to be further investigated.

\section{Drag reduction by supercavitation}

Supercavitation drag reduction refers to the creation of an air clad on the surface of a moving object, which transfers the solid-liquid interface into a solidair interface, so as to fully reduce the skin-friction 

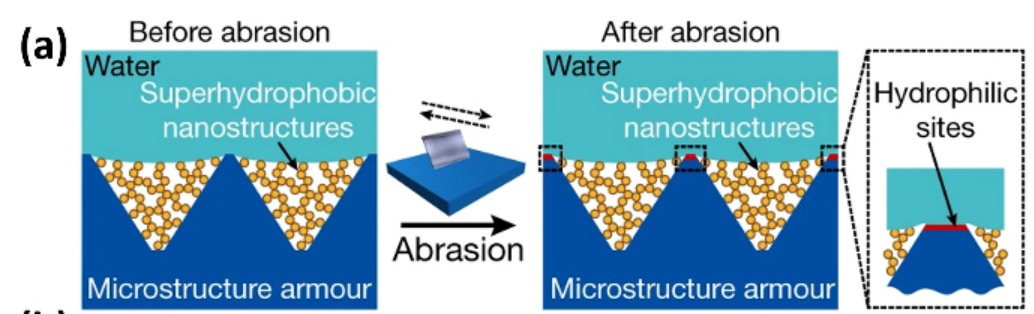

(b)

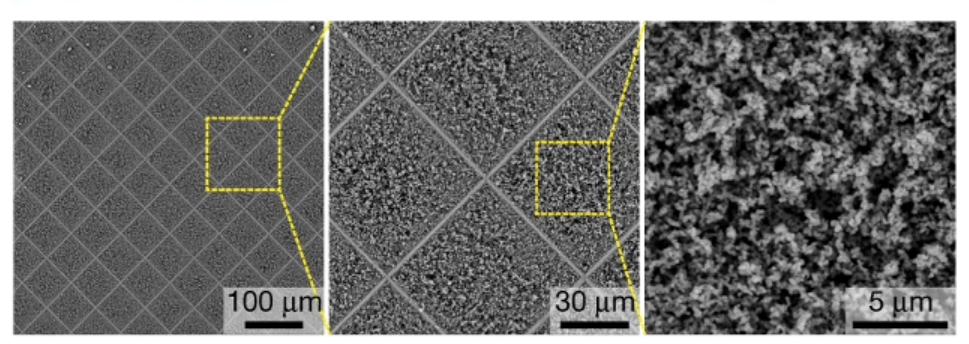

Fig. 13 Armoured superhydrophobic surface before and after abrasion: (a) Schematic diagram of test method. (b) Scanning electron micrographs of silica fractal nanostructures housed within the silicon microstructure frame after abrasion. Reproduced with permission from Ref. [14], C Springer Nature, 2020.

drag and achieve an extremely high speed, as shown in Fig. 14 [19, 20, 124, 125].

Main flow patterns of supercavitation are summarized in Fig. 15 [17]. It is concluded that both the shape of the body and the cavitator should be taken into consideration to ensure low skin-friction drag and low pressure drag.

In the experimental research of supercavitation, water-tunnel is one of the most important devices, which mainly includes a test section, diffusers, elbows, and a settling chamber, as shown in Fig. 16 [126], but

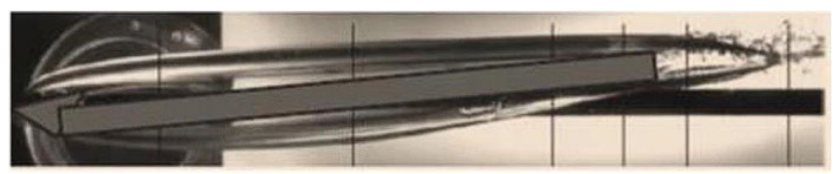

Fig. 14 Sketch of a body surrounded by a ventilated cavity. Reproduced with permission from Ref. [19], (C) Springer Nature, 2019.

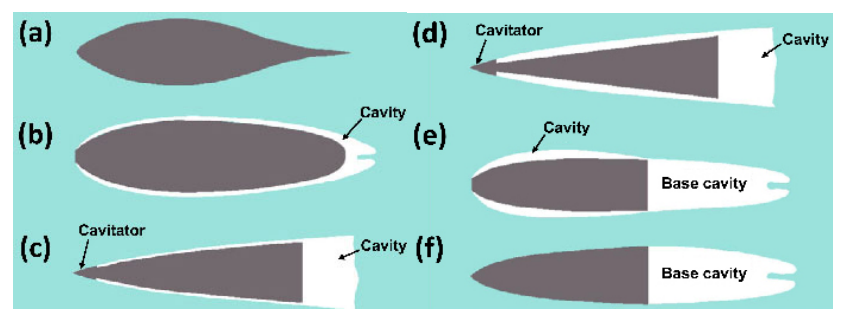

Fig. 15 Different axisymmetric flow patterns: (a, f) Unseparated flow patterns. (b, e) Supercavitating flow patterns with non-slender cavitators. (c, d) Supercavitating flow patterns with slender cavitators. $(e, f)$ Flow patterns with the base cavity. Reproduced with permission from Ref. [17], (C) Springer Nature, 2012. the flow velocity in the water-tunnel is relatively low. Meanwhile, projectile is another efficacious method which can travel at a much higher speed, although sometimes its velocity is unsteady. In the simulation study of supercavitation, the ideal fluid theory and the fully turbulent flows theory are two main computational methods widely employed, and the ideal fluid theory remains to be the most effective method yet [19].

Needless to say, the supercavitation technique is of great theoretical and practical interests due to its drag and noise reduction ability for underwater vehicles, and several successful cases have testified its tremendous potential [127, 128]. Up to now, the most well-known applications of supercavitation technology are the "Shkval" supercavitating torpedo developed by Russia, which is able to travel at speeds of up to $100 \mathrm{~m} / \mathrm{s}$ underwater. Besides, the "adaptable high speed undersea munitions" developed by the U.S. army was reported to achieve an incredible speed at $1,000 \mathrm{~m} / \mathrm{s}$ order of magnitude [129].

In the next sections, we will give a brief introduction on the preparation and the drag reduction mechanism of supercavitation, meanwhile, a discussion about the key technologies in application is draw out.

\subsection{The preparation of supercavitation}

\subsubsection{The theory of supercavitation formation}

Since supercavitation is a special case of cavitation, 


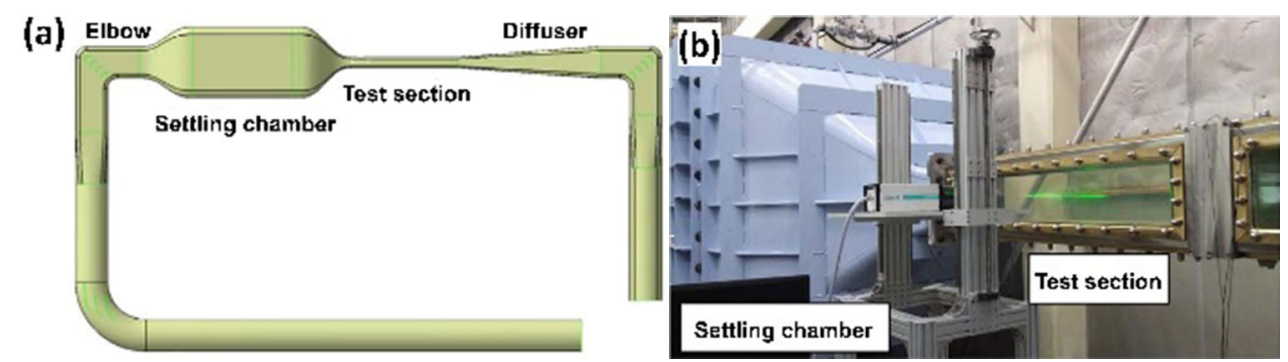

Fig. 16 Images of high-speed water-tunnel: (a) Sketch of a middle size water-tunnel model. (b) Test section of a full-scale high-speed tunnel. Reproduced with permission from Ref. [126], C Springer Nature, 2017.

first we may need to get a basic idea of cavitation - a phenomenon that the gas cores originally contained in the liquid expand rapidly and form obvious bubbles, for the fluid with a temperature lower than the boiling point, it generally occurs in a certain location where the hydrodynamic pressure drops below the vapor pressure [130, 131]. In most cases, cavitation is an undesirable phenomenon causing significant degradation in the performance, while it can also be effectively used in some occasions by proper operation, and supercavitation drag reduction is one of its most striking and ingenious applications [131, 132].

Cavitation phenomenon is usually characterized by cavitation number $(\sigma)$, as defined by Eq. (7).

$$
\sigma=\frac{P_{0}-P_{\mathrm{v}}}{\rho v^{2} / 2}
$$

where $P_{0}$ and $v$ are the pressure and flow velocity at infinite distance, $P_{\mathrm{v}}$ is the vaporization pressure of the liquid, $\rho$ is the density of the fluid.

Previous studies show that with the decrease of cavitation number, the cavitation takes on different states. When $\sigma$ is at a relatively large value, only one independent free cavity or bubble can be formed on the surface of the object, which is called floating cavitation. Then as the cavitation number decreasing, the bubble in a cloud form will appear, with the characteristics of strong vibration, intense noise, and periodic shedding. When the cavitation number is further reduced, a feed through area called sheet cavitation will gradually form. And when $\sigma<0.1$, the sheet cavity will cover the whole surface of the flow object, which is known as supercavitation [127].

Hereby we can see that small cavitation numbers are required for supercavitation to occur, and in the following sections we will present the implementation methods developed based on this principle.

\subsubsection{The preparation methods of supercavitation}

Concerning about the preparation of supercavity, specific methods have been developed from varies ways, such as increasing the free stream velocity, decreasing submersion depth, and increasing the cavity pressure through ventilation [133]. Generally they are concluded into natural supercavitation and ventilated supercavitation two main directions [134].

\section{(1) Natural supercavitation}

Natural supercavitation refers to the supercavity formed naturally at high enough velocity (more than $50 \mathrm{~m} / \mathrm{s}$ ) or low enough hydrostatic pressure.

As we mentioned above, physical experiments of natural supercavitation usually carried out with small projectiles or bullets, and always accompanied by numerical simulations to analyze supercavitation characteristics. A typical example can be seen in the study accomplished by Jiang and Li [135], where the simulation of natural supercavitations in drag-reducing solutions with additives was conducted after physics experiments, as shown in Fig. 17, which gave a clearer insight into the function mechanism of additives on
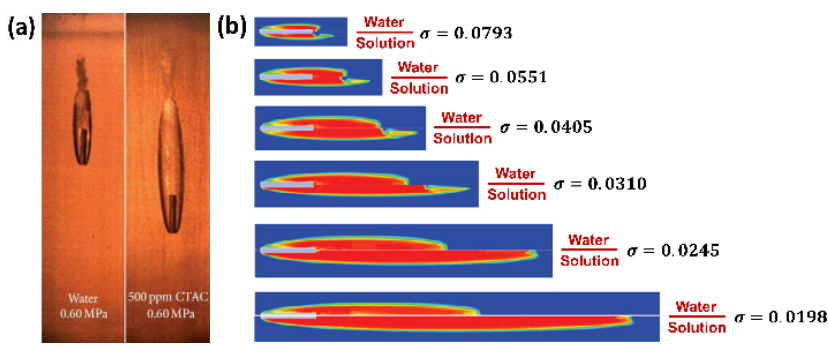

Fig. 17 Comparisons of supercavities in water and drag-reducing solution: (a) Experimental results of supercavities formed around bullets. (b) Simulation results at various cavitation numbers. Reproduced with permission from Ref. [135], (c) The authors, 2014. 
natural supercavitation.

Although the facility requirements for small-size experiments are comparably low, it is quite hard to achieve the preparation and the maintenance of supercavity on full-size underwater vehicles naturally. Thereby, this method is seldom used in practice.

\section{(2) Ventilated supercavitation}

Ventilated supercavitation, also known as artificial supercavitation, refers to the method to form supercavity by ventilation injection. Since a much lower speed is required to achieve supercavitation, it has been studied in a wide rage [136].

Since Reichardt proved the feasibility of achieving supercavitation by artificial ventilation in 1946, multiple researches about the influence of ventilation volume, gravity, the characters of ventilated supercavitation and so on have been raised continuously $[19,124,137,138]$. And the experiments conducted by Zhang et al. [138] show the development procedure of ventilated supercavitation clearly (see Fig. 18), from the bubbles formed at the cavitator to the ellipsoidal partial cavitation, and finally transited to supercavitation.

According to the reported articles, the preparation methods of ventilated supercavitation can be divided into three types. The first type is to inject gas from the head of the object towards the direction of liquid flow by using an air jet device, as shown in Fig. 19(a). In this case, the gas pressure must be higher than the liquid pressure at the static point of the object head, and the gas speed must be more than 28 times of the liquid flow rate. The second way is to use the liquid injection device to spray liquid from the object head towards the flow direction, and injecting gas into the stagnant area at the same time, as shown in Fig. 19(b). This method is based on the idealized condition that the tail pressure is fully recovered to produce thrust, which transfers the static point of the object head to the liquid flow. The third method is injecting air into the separated part to produce a stable and smooth cavitation when the object moves at high speed and the cavitation occurs at the sharp edge of the cavitation generator, as shown in Fig. 19(c). When supercavitation is completely formed, air can be replenished in any part of the object, and it is the most common way to achieve supercavitation at present.

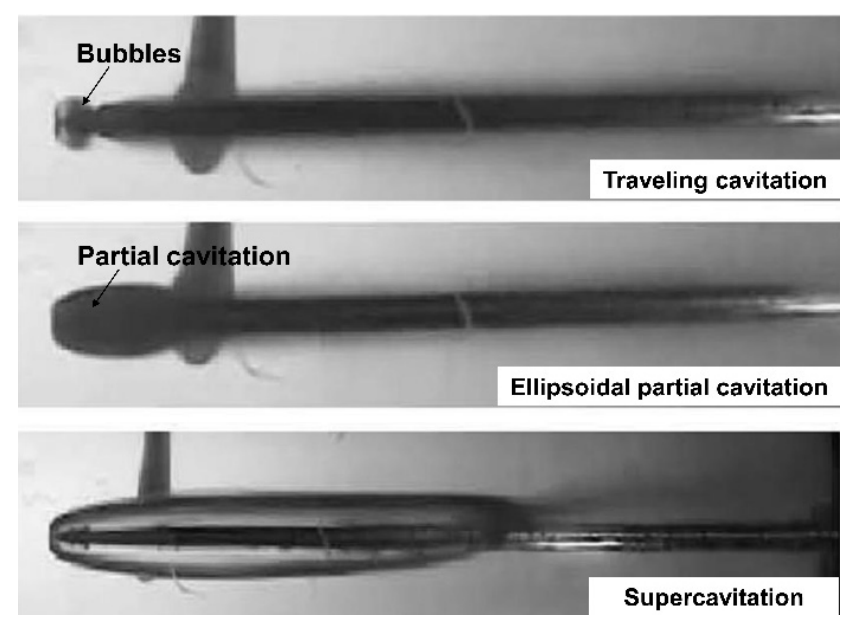

Fig. 18 Development procedure of ventilated supercavitation: from bubbles to supercavitation. Reproduced with permission from Ref. [138], (c) Elsevier, 2007.
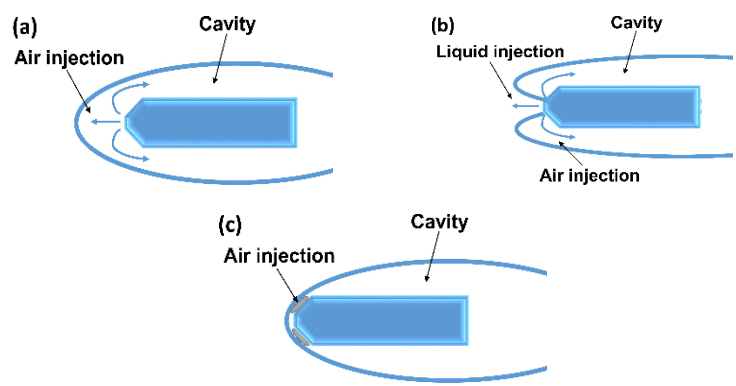

Fig. 19 Schematic diagram of supercavitation preparation by different ventilated methods.

In general, artificial ventilation is a conducive way for the rapid generation of supercavitation, but there are still many problems to be solved, such as the reasonable control of ventilation rate and the closure mode [128], and the feasible structure for realization, which need to be studied further.

\subsection{The drag reduction mechanism and key technologies of supercavitation}

\subsubsection{The drag reduction mechanism}

Supercavitation exhibits a splendid drag-reducing performance with a drag reduction rate more than $90 \%$. A research carried out by Savchenk [18] pointed out that for slender gyros, when $\sigma$ is 0.01 , the drag reduction percentage can reach up to $95 \%$, and it is speculated that when $\sigma$ is 0.0001 , the drag reduction percentage can be $99.9 \%$.

The main mechanism is transferring the solid-liquid interface to solid-air contact, thus the viscosity is 
reduced sharply, and the friction resistance declines accordingly. And the smaller velocity gradient of the gas phase can also result in a reduction of the shear stress. Meanwhile, with the decrease of $\sigma$ value, the volume ratio of dispersed droplets in the cavity gets smaller and the air tends to be thinner, which lead to a further weakening of the tangential momentum exchange.

\subsubsection{Key problems in practical application}

Supercavitation is an attractive way for solid-liquid drag reduction, however, it is not so commonly applied to practical usage, on account of the key problems unsolved.

\section{(1) Stability of Supercavitation}

The instability of supercavity in operation is the first trouble in its practical application. To solve this problem, the effect of parameters and operating conditions on the stability of vehicles is widely studied [139, 140]. And ventilation forced instabilities, free shear instabilities, bubble oscillation, and self-induced oscillation are concluded to be the main influence factors [141]. Moreover, it is observed that the objects pitch up and down while moving, therefore the aft portion may intersect the cavity, which can result in the changes of the wetted contact area, and take a great impact on the stability of the supercavitating vehicle, and Lee et al. [142] proved that the pressure near the water contact area changes dramatically.

The controlling methods are developed from two aspects. On the one hand, it is implemented by building a closed-loop control system that monitors the vehicle state and adjusts the facilities such as ventilation device and cavitator in real time. But this method is rarely reported. On the other hand, appropriate hydrodynamic layout and optimal design of cavitator, model body, and tail wing are proved to be feasible at this stage [129, 133, 143].

In addition, the instability caused by the dramatic change of fluid dynamic during the formation of supercavity is generally treated by increasing the propulsion force, therefore reducing the generation time, or optimizing front profiles of the supercavitating vehicles [144], whereas high pulsations of vehicle tail and high noise emission issues may then arise [138].

\section{(2) Other problems}

Effective control and precision guidance is another key technology in the application of supercavitating vehicles. Experiments carried out by scientists in Germany have shown that the trajectory of a supercavitating vehicle can be controlled by the proper motion of the object head cone [145]. And the thrust vector system was proved to be able to control the motor behavior of underwater supercavitating vehicles. However, so far 3D real-time monitor and precise guidance is still an unsolved problem [139, 146].

Besides, it should be noticed that propulsion technology is also a key point of supercavitation application. Rocket engines are usually used to generate thrust, but the limited voyage mileage and propulsive force decrease with the depth of water restrict its application prospect, which should be taken into consideration [147].

\subsection{Summary}

In this part we give a general introduction about supercavitation, its great application potential can be clearly seen. However, although it has been developed for decades, the prediction of air demand and drag reduction rate, the impact of the air supply method for ventilated cavitation [19], the application of a 3D trajectory tracking controller, and the robust constraint fulfillment of supercavitating vehicles remain to be open issues.

To overcome these problems and promote further development in supercavitation, theoretical, experimental, and numerical methods need to be applied comprehensively in research. And numerical simulation of supercavitation will continue to be an important means of future research, as it can significantly save the cost of the experiments by beforehand simulation and prediction, and provide effective analyses after the experiments. In addition, with the combination with other new technologies such as artificial neural networks [127], more efficiency approaches may be invented and shed light on the fundamental understanding and application of supercavitation.

\section{Drag reduction by polymer additives}

Polymer drag reduction is one of the hottest issues 
in drag reduction area, generally it is working by dissolving a small amount of polymer additives into the turbulence flow, while the ability of drag reduction is up to $80 \%$ with minute concentrations [30, 31].

Scientific and systematic researches about polymer drag reduction were started from Toms' [29] finding that the flow friction of polymer solution is smaller than that of pure solvent, by an experiment carried out with chlorobenzene solution containing polymethylmethacrylate (PMMA) in the pipeline. This is the phenomenon later known as "Tom's effect". After that, the great potential of polymer drag reduction has aroused much interests among scientists. As a result, researches about the characteristics of polymer additives, the influence factors and the maximum drag reduction rate, the mechanism and the application of polymer reduction etc. are carried out worldwide. Noticeably, a new function way of polymer called molecular brush was experimentally studied by Klein et al. [148-150], in which polymers adsorbed on the wall by electrostatic force and the existence of hydration force or electric double layer force can produce an ultra-low friction. This provides a new direction for the further development of polymer drag reduction.

The first commercial use of a polymeric dragreducing additive was implemented successfully in a crude oil pipeline in the Trans Alaska Pipeline System during 1979, it is reported that the addition of drag reduction additives has increased crude oil production by up to $30 \%$ [151]. Inspired by the successful application of polymer additives in oil transportation, the investigations focus on the usage of polymer in other field like water delivery system [152], firefighting [153], district heating and cooling [154], petroleum loading and offloading as well as in refineries [155], ship navigation, biomedical system [156], and nuclear district heating system [157] have been carried out continuously.

In this part, we will give a general introduction of the drag-reducing polymer additives and the representative theories of polymer drag reduction mechanism.

\subsection{Drag-reducing polymer additives and a key problem in application}

Polymer drag reducing agents can be generally divided into oil soluble and water soluble, and they are used in different conditions due to their own characteristics. Apart from this, polymer additives do have something in common.

\subsubsection{Characteristics of drag-reducing polymer additives}

According to research, the performance of polymers in drag reduction is corresponding to its dissolution rate, concentration, molecular weight, length and structure, and so on [30, 158-160]. A typical result is shown in Fig. 20 [161].

Here we summarize some detail results proposed by researchers. Benzi [162] stated that the influence of polymer concentration on drag reduction is related to the maximum tensile strength of the polymer. Besides, a good compatibility with solvent and a relatively small added amount are also essential to
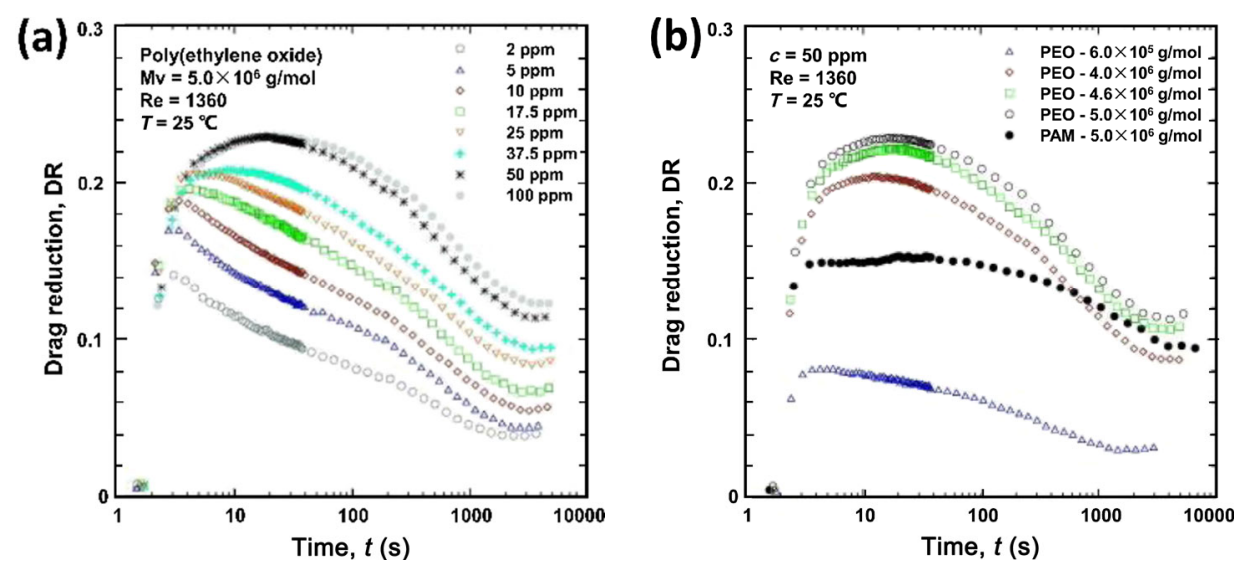

Fig. 20 Effects of parameters on drag reduction: (a) Concentration. (b) Different polymers. Reproduced with permission from Ref. [161], (C) Elsevier, 2012. 
meet the practical demands. Shanshool et al. [163] found that under certain concentration and Reynolds number, the higher the molecular weight, the better the drag reduction effect. In addition, synthetic polymers with wide molecular weight distributions were proved to be effective drag-reducing polymers [164]. For the influence of molecular structure, it is believed that a linear structure for a given molecular weight is instrumental in drag reduction, while contrarian views are given about whether branch chains beneficial or not [165-167].

\subsubsection{A key problem in application}

Studies show that the efficiency of those additives is not constant, polymer molecules are easy to degrade (also called de-aggregation, as shown in Fig. 21 [168]) and lose their ability of drag-reducing in turbulence flow. Since the degradation process is irreversible, it has become the major obstacle in the application of polymer additives.

Needless to say, degradation phenomenon has received lots of attention. Early in 1989, Nguyen and Kausch [169] had pointed out that residence time of the polymers in the flow, shear rate, concentration of the polymers, temperature, and polymer type are several determined factors of degradation. Furthermore, Pereira et al. [161] analyzed the impact of molecular weight, Reynolds number, etc. with a cylindrical double gap rheometer device. Zhang et al. [170] found that the drag reduction ability decreases with the increase of temperature, which is due to the increase of molecular thermal motion and the destruction of intermolecular interaction at high temperature. Moussa and Tiu [171] suggested that owing to the high stretcher strain of polymer molecules, most of the degradation occurs in the entrance region. And Brostow $[172,173]$ proposed a hypothesis that the degradation rate of polymer additives is identical to the molecular weight decrease rate. But latterly some results showed that Brostow's assumption is not adapted for occasions like circulating flow or pipe flow [174, 175]. Zhang et al. [176, 177] did further studies from a new molecular view, their theoretical analysis and experimental data suggested that the failure of Brostow' assumption is due to the presence of aggregates in polymer solutions, and they clarified that the broken

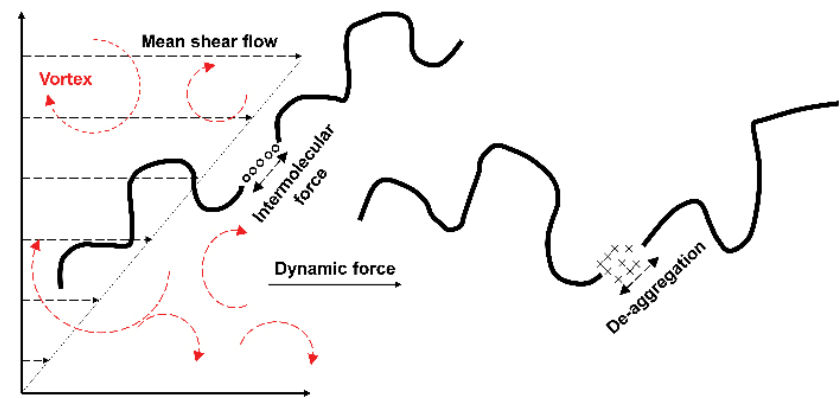

Fig. 21 Sketch of polymer de-aggregation. Reproduced with permission from Ref. [168], (C) Elsevier, 2020.

of polymer chains result in the loss of drag-reducing effect, and high molecular weight and linear chain additives are more vulnerable in turbulent flow.

\subsection{The mechanism of polymer drag reduction}

Although polymer additives have been applied in many cases successfully, the underlying physics is still poorly understood. In order to find out the drag reduction mechanism of polymer additives, a large number of verification methods have been developed in the past few decades. Generally, it is studied by comparing the turbulence statistics and the turbulent coherent structure before and after adding polymers, or by studying the variation of polymer molecular characteristics in turbulence.

And many theories have been proposed in succession. Such as Virk [159, 178] considered that the interference of polymer molecules on turbulence and the extension of macromolecules participate in the drag reduction. Brostow [179] recommended that solvation is the main reason for drag reduction, the solvates formed by macromolecular chains in the fluid help to protect the solvent molecules from the influence of turbulence, thus reducing the resistance.

Apart from these viewpoint, elastic theory and viscous anisotropic theory are more widely accepted, hereafter we will give a detail introduction.

\subsubsection{Elastic theory}

A main interpretation of polymer drag reduction was due to Lumley [180, 181], it is argued that molecular expansion is responsible for the different behavior in the sublayer and buffer layer. He proposed that a significant viscoelastic effect would occur under certain conditions and assumed that the solution behaves 
as a strong viscous fluid in the turbulent region. It is generally accepted but also facing some questions with the continuous improvement of research. Hence, an elastic theory was further developed by de Gennes [182].

According to de Gennes' theory, the energy dissipated by small-scale vortex can be absorbed and stored in the extended polymer microstructure in the high strain rate region. A basic idea is that the polymers will not be fully stretched, but those partially stretched polymers can store elastic energy and interfere with cascade systems in turbulence [182]. When the energy storage microstructure diffuses to the low strain rate region, it will relax to the irregular linear cluster, and the stored energy will be released to the low wave number vortex in the form of elastic shear stress wave, which greatly reduces the dissipation of flow kinetic energy of the fluid and realizes drag reduction.

A similar mechanism was put forward by Rabin et al. [183, 184] based on the theoretical analyses of vorticity disturbance in axisymmetric stretching flow of dilute polymer solution, he considered that the elastic energy storage of polymers suppresses the cascade of energy and enhances the large-scale vorticity. That means, when the Reynolds stress of turbulent fluid and the elastic stress of polymer solution are in the same order of magnitude, the energy transfer chain is cut off, and the energy dissipation cannot reach the final state, thus the flow resistance decreases.

This hypothesis can not only explain the drag reduction phenomena of many viscoelastic polymers, but also can be used in the quantitative calculation of

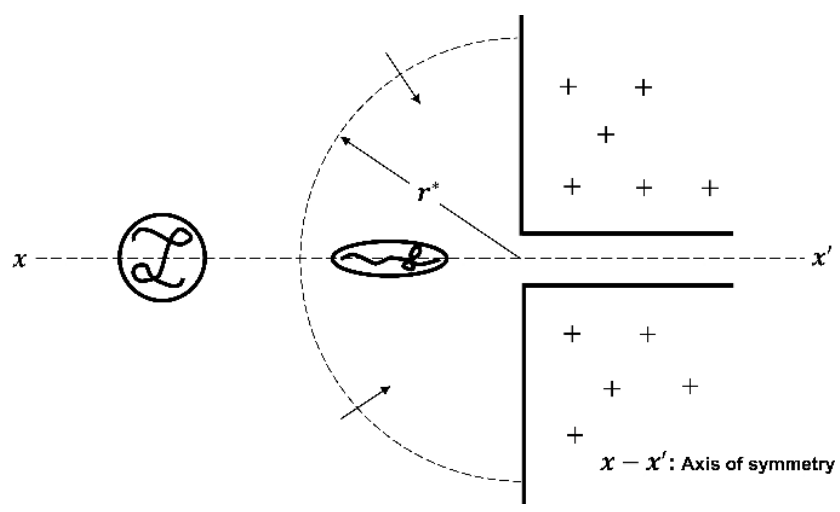

Fig. 22 An example of longitudinal shear at the entry of a capillary ( $r *$ is the elongation). Reproduced with permission from Ref. [182], (c) Cambridge University Press, 1990. the drag reduction rate. However, the development of the viscous anisotropic theory of Tooder et al. [185] brings it a big challenge.

\subsubsection{Viscous anisotropic theory}

Compare to elastic theory, there are other experiments suggested that the mechanism of drag reduction is the anisotropy caused by the stretching and orientation of polymer molecules in the turbulent boundary layer.

In order to learn more about the role of anisotropy and elasticity in polymer drag reduction, Tooder et al. [185] used laser Doppler velocimetry (LDV) to measure the turbulence statistics and turbulent kinetic energy spectrum near the wall, and applied direct numerical simulation (DNS) to investigate the effects of polymers on the flow, with two different models named viscous anisotropic (VA) model and viscoelastic anisotropic (VEA) model developed respectively.

The calculation results show that the first model considering the viscous anisotropic effects is in good agreement with the experimental data, while the second model with the extension of an elastic component of polymer is quite different from the experimental data [185]. This result supports Tooder's viscous anisotropic theory, which is a challenge to the traditional viscoelastic theory.

To date, although some understanding of polymer drag reduction has been gained, there is no recognized model that can fully explain the whole phenomenon, and a more practical mechanism is expected to be developed.
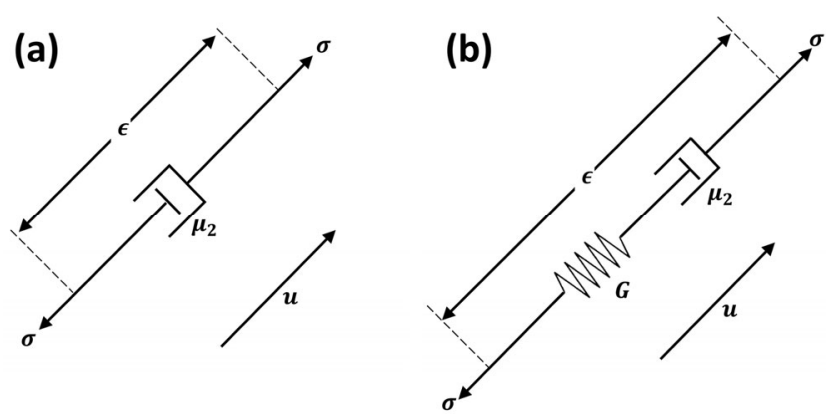

Fig. 23 Mechanical model of (a) the viscous anisotropic model and (b) the viscoelastic anisotropic model. Where $u$ is the velocity vector, $\mu_{2}$ is a constant related to the solvent viscosity, $\sigma$ is the stress (force), $\epsilon$ is the strain (extension), $G$ is the elastic modulus. Reproduced with permission from Ref. [185], (C) Cambridge University Press, 1997. 


\subsection{Summary}

From the review of polymer drag reduction given above, we can see that the successful application of polymer additives in oil pipeline and the attractive drag reduction rate have made polymer drag reduction a hot topic in recent decades. In the future, the application range of polymer drag reduction needs to be further expanded, as most studies are limited in the laboratory at present. To achieve this, the mechanism of polymer drag reduction needs to be further explored. Cheerfully, with the development of technologies, more advanced facilities are available in experiments, which provide the possibility for the further development in the investigation of function mechanism. Another issue we should take into consideration is influence of synthetic polymer additives on environment, and natural organic polymers may provide a new choice for this matter.

\section{Comparison of different drag reduction methods}

Except the drag reduction methods introduced in the previous parts, there are also some other wide studied methods such as surfactant additives, microbubbles, compliant wall, oscillating wall, and superlubricity. Here we compare the reported drag reduction rates, advantages and limitations, and typical applications of all these methods, as listed in Table 1, so as to give a more comprehensive understanding on solid-liquid interface drag reduction.

\section{Conclusions and prospects}

Drag reduction at solid-liquid interfaces has attracted wide attention of scholars because of its universality and the great value in application to reduce energy consumption, increase object's speed and so on. Kinds of drag reduction methods have been putting forward and studied in depth, and some of the most influential drag reduction methods are summarized respectively in this article.

From the introduction and discussion above we can draw a conclusion that improving the practical application ability of varied drag reduction methods is still a key problem waiting to be solved, and the function mechanisms of drag reduction in different situations need to be further clarified to provide more guidance. In this regard, more efforts should be made to develop or induce new research means and facilities to promote the research. It is predictable that future studies of drag reduction will be conducted by multidisciplinary approaches, and numerical simulation will play an important role.

Besides, the combination of various methods may result in a better performance in drag reduction, and we think that there could be two ways of combination. The first is to choose one method as the main function part, and induce other proper one or more as auxiliary means to enhance the drag reduction effect, such as the combination of superhydrophobic surfaces and the heating wall, where heating wall is applied to produce air layers to improve the drag reduction rate and durability of superhydrophobic surfaces [202]. In addition, the association of surfactant additives and supercavitation, in which the additives effectively enhance supercavitating process and modify the turbulence structures, is also a typical case. The other way is the normal combination of two or more methods to achieve better results, for instance, add polymer additives into the transported fluid while the pipeline is also superhydrophobic treated. As for the selection principle of drag reduction methods, we believe that effectiveness, environmental friendliness, low-cost, and long-term stability are four of the most important factors to be concerned, which should be taken into consideration whether one or more methods are selected.

Furthermore, the future of drag reduction not only lies in these well-developed methods, but also requires researchers to seek new answers for enhancing solid-liquid interface drag reduction. On this point, as mentioned at the beginning, we believe that superlubricity may provide a considerable solution.

\section{Acknowledgements}

The work was financially supported by the National Natural Science Foundation of China (Nos. 51527901 and 51922058). 
Table 1 A comparison of different drag reduction methods.

\begin{tabular}{|c|c|c|c|c|}
\hline Methods & $\begin{array}{l}\text { Initial time of } \\
\text { study }\end{array}$ & $\begin{array}{l}\text { Drag reduction } \\
\text { rate }\end{array}$ & Advantages and limitations & Typical applications \\
\hline $\begin{array}{c}\text { Microstructure } \\
{[10,12,13,62,186-190]}\end{array}$ & $\begin{array}{l}\text { mid-20th } \\
\text { century }\end{array}$ & $3.75 \%-14 \%$ & $\begin{array}{l}\cdot \text { Simple and effective } \\
\cdot \text { Energy-efficient } \\
\cdot \text { Difficult to use in large objects } \\
\cdot \text { Only capable in turbulent flow } \\
\cdot \text { Poor persistence }\end{array}$ & $\begin{array}{l}\cdot \text { Rowing boats } \\
\cdot \text { Swimsuits } \\
\cdot \text { Airbus aircraft (in air) } \\
\cdot \text { Helmets (in air) } \\
\cdot \text { Golf balls (in air) }\end{array}$ \\
\hline $\begin{array}{c}\begin{array}{c}\text { Superhydrophobic } \\
\text { surface }\end{array} \\
{[16,87,90,91,107,109,} \\
110,112,117,191]\end{array}$ & $1990 \mathrm{~s}$ & $5 \%-56.9 \%$ & $\begin{array}{l}\cdot \text { Environmental protection } \\
\cdot \text { Both effective in laminar flow } \\
\text { and turbulent flow } \\
\text {-Wide range of application } \\
\text {-Susceptible to surface adhesion } \\
\cdot \text { Hard to steadily sustain }\end{array}$ & $\begin{array}{l}\cdot \text { Surface vessels and submarines } \\
\cdot \text { Microfluidic devices } \\
\cdot \text { Transportation pipelines } \\
\cdot \text { Syringe tips }\end{array}$ \\
\hline $\begin{array}{c}\text { Polymer additives } \\
{[29-31,110,151,165,} \\
192,193]\end{array}$ & 1948 & $20 \%-80 \%$ & $\begin{array}{l}\text {-Effective with a small amount of } \\
\text { additives } \\
\text {-Susceptible to mechanical } \\
\text { degradation (irreversible) } \\
\text {-Reduced heat transfer ability }\end{array}$ & $\begin{array}{l}\text {-Crude oil and water flow } \\
\text { pipeline transportation } \\
\cdot \text { Slurry or hydraulic capsule } \\
\text { pipeline transportation } \\
\text {-Suppression of atherosclerosis }\end{array}$ \\
\hline $\begin{array}{c}\text { Surfactant additives } \\
\qquad[194-196]\end{array}$ & $1980 \mathrm{~s}$ & Max. $83 \%$ & $\begin{array}{l}\text {-Self-assembly after mechanical } \\
\text { degradation } \\
\cdot \text { - Low environmental impact } \\
\cdot \text { React with ions to produce } \\
\text { precipitation } \\
\cdot \text { Decrease heat transfer }\end{array}$ & $\begin{array}{l}\text {-Small-scale district heating } \\
\text { and cooling (DHC) systems }\end{array}$ \\
\hline $\begin{array}{c}\text { Supercavitation } \\
{[18,20,145,147]}\end{array}$ & $1970 s$ & $>90 \%$ & $\begin{array}{l}\cdot \text { Remarkable drag reduction rate } \\
\cdot \text { Difficult to implement } \\
\cdot \text { High-cost }\end{array}$ & $\begin{array}{l}\cdot \text { Underwater weapons and } \\
\text { vehicles } \\
\cdot \text { Hydrofoil propellers }\end{array}$ \\
\hline $\begin{array}{c}\text { Microbubbles } \\
{[23,197]}\end{array}$ & 1973 & $5 \%-80 \%$ & $\begin{array}{l}\cdot \text { High drag reduction efficiency } \\
\text {-No ship's hull shape change } \\
\text { requirements } \\
\text {-Clean and pollution-free } \\
\text {-Additional energy or gas-providing } \\
\text { devices are needed } \\
\text {-Instability of bubbles }\end{array}$ & -Ships \\
\hline $\begin{array}{l}\text { Oscillating wall } \\
{[32-38,196,198]}\end{array}$ & $1990 \mathrm{~s}$ & $10 \%-45 \%$ & $\begin{array}{l}\cdot \text { Effective } \\
\cdot \text { A considerable amount of energy } \\
\text { is required to work } \\
\cdot \text { Not well understood }\end{array}$ & Not reported yet \\
\hline $\begin{array}{l}\text { Compliant wall } \\
{[40-45,199,200]}\end{array}$ & $1960 s$ & $2.7 \%-12 \%$ & $\begin{array}{l}\cdot \text { Simple, cost effective } \\
\cdot \text { Easy to retrofit } \\
\cdot \text { Need to be replaced frequently }\end{array}$ & Not reported yet \\
\hline $\begin{array}{l}\text { Superlubricity } \\
{[46-53,55,201]}\end{array}$ & $1990 \mathrm{~s}$ & $20 \%$-appr. $100 \%$ & $\begin{array}{l}\cdot \text { Remarkable drag reduction rate } \\
\text {-Excellent energy saving effect } \\
\cdot \text { Can be flexibly implemented in } \\
\text { a variety of ways } \\
\text {-High requirements for implemen- } \\
\text { tation conditions }\end{array}$ & $\begin{array}{l}\text { Supposed to be applied in: } \\
\cdot \text { Watercraft } \\
\cdot \text { Fluid machinery } \\
\cdot \text { MEMS } \\
\cdot \text { Biological joints, etc. }\end{array}$ \\
\hline
\end{tabular}


Open Access This article is licensed under a Creative Commons Attribution 4.0 International License, which permits use, sharing, adaptation, distribution and reproduction in any medium or format, as long as you give appropriate credit to the original author(s) and the source, provide a link to the Creative Commons licence, and indicate if changes were made.

The images or other third party material in this article are included in the article's Creative Commons licence, unless indicated otherwise in a credit line to the material. If material is not included in the article's Creative Commons licence and your intended use is not permitted by statutory regulation or exceeds the permitted use, you will need to obtain permission directly from the copyright holder.

To view a copy of this licence, visit http://creativecommons.org/licenses/by/4.0/.

\section{References}

[1] Alben S, Shelley M, Zhang J. Drag reduction through selfsimilar bending of a flexible body. Nature 420(6915): 479-481 (2002)

[2] Fukuda K, Tokunaga J, Nobunaga T, Nakatani T, Iwasaki $\mathrm{T}$, Kunitake Y. Frictional drag reduction with air lubricant over a super-water-repellent surface. J Mar Sci Technol 5(3): 123-130 (2000)

[3] Sun Y W, Yan X P, Yuan C Q, Bai X Q. Insight into tribological problems of green ship and corresponding research progresses. Friction 6(4): 472-483 (2018)

[4] Ushida A, Hasegawa T, Narumi T. Drag reduction for liquid flow through micro-apertures. J Non-Newton Fluid Mech 165(21-22): 1516-1524 (2010)

[5] Wu L Y, Jiao Z B, Song Y Q, Liu C H, Wang H, Yan Y Y. Experimental investigations on drag-reduction characteristics of bionic surface with water-trapping microstructures of fish scales. Sci Rep 8(1): 12186 (2018)

[6] Xu M C, Grabowski A, Yu N, Kerezyte G, Lee J W, Pfeifer B R, Kim C J C. Superhydrophobic drag reduction for turbulent flows in open water. Phys Rev Applied 13(3): 034056 (2020)

[7] Daniello R J, Waterhouse N E, Rothstein J P. Drag reduction in turbulent flows over superhydrophobic surfaces. Phys Fluids 21(8): 085103 (2009)

[8] Bidkar R A, Leblanc L, Kulkarni A J, Bahadur V, Ceccio S L, Perlin M. Skin-friction drag reduction in the turbulent regime using random-textured hydrophobic surfaces. Phys
Fluids 26(8): 085108 (2014)

[9] Bixler G D, Bhushan B. Fluid drag reduction with shark-skin riblet inspired microstructured surfaces. Adv Funct Mater 23(36): 4507-4528 (2013)

[10] $\mathrm{Pu} \mathrm{X,} \mathrm{Li} \mathrm{G} \mathrm{J,} \mathrm{Liu} \mathrm{Y} \mathrm{H.} \mathrm{Progress} \mathrm{and} \mathrm{perspective} \mathrm{of} \mathrm{studies}$ on biomimetic shark skin drag reduction. ChemBioEng Rev 3(1): 26-40 (2016)

[11] Lang A W, Motta P, Hidalgo P, Westcott M. Bristled shark skin: a microgeometry for boundary layer control? Bioinspir Biomim 3(4): 046005 (2008)

[12] Dean B, Bhushan B. Shark-skin surfaces for fluid-drag reduction in turbulent flow: A review. Phil Trans $R$ Soc $A$ Math Phys Eng Sci 368(1929): 4775-4806 (2010)

[13] Bechert D W, Bruse M, Hage W. Experiments with threedimensional riblets as an idealized model of shark skin. Exp Fluids 28(5): 403-412 (2000)

[14] Wang D H, Sun Q Q, Hokkanen M J, Zhang C L, Lin F Y, Liu Q, Zhu S P, Zhou T F, Chang Q, He B, et al. Design of robust superhydrophobic surfaces. Nature 582(7810): 55-59 (2020)

[15] Lee C, Choi C H, Kim C J. Superhydrophobic drag reduction in laminar flows: A critical review. Exp Fluids 57(12): 176 (2016)

[16] Zhang X, Shi F, Niu J, Jiang Y G, Wang Z Q. Superhydrophobic surfaces: From structural control to functional application. J Mater Chem 18(6): 621-633 (2008)

[17] Nesteruk I. Drag effectiveness of supercavitating underwater hulls. In Supercavitation. Nesteruk I, Ed. Berlin, Heidelberg: Springer, 2012: 79-106.

[18] Savchenko Y N. Supercavitation-problems and perspectives. In Proceedings of the 4th International Symposium on Cavitation, California, USA, 2001: 20-23.

[19] Amromin E L. Challenging problems on ventilated cavitation and paths to their computational solutions. J Marine Sci Appl 18(3): 260-270 (2019)

[20] Wang J D, Wang B, Chen D R. Underwater drag reduction by gas. Friction 2(4): 295-309 (2014)

[21] Ceccio S L. Friction drag reduction of external flows with bubble and gas injection. Annu Rev Fluid Mech 42(1): 183-203 (2010)

[22] McCormick Dr M E, Bhattacharyya Dr R. Drag reduction of a submersible hull by electrolysis. Nav Eng $J$ 85(2): 11-16 (1973)

[23] Madavan N K, Deutsch S, Merkle C L. Reduction of turbulent skin friction by microbubbles. Phys Fluids 27(2): 356-363 (1984)

[24] Skudarnov P V, Lin C X. Drag reduction by gas injection into turbulent boundary layer: Density ratio effect. Int $J$ Heat 
and Fluid Flow 27(3): 436-444 (2006)

[25] Kumagai I, Takahashi Y, Murai Y. Power-saving device for air bubble generation using a hydrofoil to reduce ship drag: Theory, experiments, and application to ships. Ocean Eng 95: 183-194 (2015)

[26] Jagdish B N, Brandon T Z X, Kwee T J, Dev A K. Experimental study of air layer sustainability for frictional drag reduction. J Ship Res 58(1): 30-42 (2014)

[27] Kanai A, Miyata H. Direct numerical simulation of wall turbulent flows with microbubbles. Int $J$ Numer Meth Fluids 35(5): 593-615 (2001)

[28] Min T, Yoo J Y, Choi H, Joseph D D. Drag reduction by polymer additives in a turbulent channel flow. J Fluid Mech 486: 213-238 (2003)

[29] Toms B A. Some observations on the flow of linear polymer solutions through straight tubes at large Reynolds numbers. In Proceedings of the 1st the International Congress on Rheology, Amsterdam, North Holland, 1948: 135-138.

[30] Asidin M A, Suali E, Jusnukin T, Lahin F A. Review on the applications and developments of drag reducing polymer in turbulent pipe flow. Chinese J Chem Eng 27(8): 1921-1932 (2019)

[31] Kenis P R. Drag reduction by bacterial metabolites. Nature 217(5132): 940-942 (1968)

[32] Jung W J, Mangiavacchi N, Akhavan R. Suppression of turbulence in wall-bounded flows by high-frequency spanwise oscillations. Phys Fluids A Fluid Dyn 4(8): 1605-1607 (1992)

[33] Laadhari F, Skandaji L, Morel R. Turbulence reduction in a boundary layer by a local spanwise oscillating surface. Phys Fluids 6(10): 3218-3220 (1994)

[34] Baron A, Quadrio M. Turbulent drag reduction by spanwise wall oscillations. Appl Sci Res 55(4): 311-326 (1995)

[35] Choi K S, Clayton B R. The mechanism of turbulent drag reduction with wall oscillation. Int J Heat Fluid Flow 22(1): 1-9 (2001)

[36] Quadrio M, Ricco P. Critical assessment of turbulent drag reduction through spanwise wall oscillations. J Fluid Mech 521: 251-271 (2004)

[37] Quadrio M, Ricco P, Viotti C. Streamwise-travelling waves of spanwise wall velocity for turbulent drag reduction. J Fluid Mech 627: 161-178 (2009)

[38] Tamano S, Itoh M. Drag reduction in turbulent boundary layers by spanwise traveling waves with wall deformation. J Turbul 13: N9 (2012)

[39] Muralikrishnan R, Kumaran V. Experimental study of the instability of the viscous flow past a flexible surface. Phys Fluids 14(2): 775-780 (2002)
[40] Pavlov V V. Dolphin skin as a natural anisotropic compliant wall. Bioinspir Biomim 1(2): 31-40 (2006)

[41] Sternberg J. A theory for the viscous sublayer of a turbulent flow. J Fluid Mech 13(2): 241-271 (1962)

[42] Liu E Y, Li L Y, Wang G, Zeng Z X, Zhao W J, Xue Q J. Drag reduction through self-texturing compliant bionic materials. Sci Rep 7(1): 40038 (2017)

[43] Choi K S, Yang X, Clayton B R, Glover E J, Atlar M, Semenov B N, Kulik V M. Turbulent drag reduction using compliant surfaces. Proc R Soc Lond A Mat Phys Eng Sci 453(1965): 2229-2240 (1997)

[44] Gad-el-Hak M. Compliant coatings: A decade of progress. Appl Mech Rev 49(10): S147-S157 (1996)

[45] Carpenter P W, Davies C, Lucey A D. Hydrodynamics and compliant walls: Does the dolphin have a secret? Curr Sci 79(6): 758-765 (2000)

[46] Luo J B, Zhou X. Superlubricitive engineering-Future industry nearly getting rid of wear and frictional energy consumption. Friction 8(4): 643-665 (2020)

[47] Song Y M, Mandelli D, Hod O, Urbakh M, Ma M, Zheng Q $\mathrm{S}$. Robust microscale superlubricity in graphite/hexagonal boron nitride layered heterojunctions. Nat Mater 17(10): 894-899 (2018)

[48] Hod O, Meyer E, Zheng Q S, Urbakh M. Structural superlubricity and ultralow friction across the length scales. Nature 563(7732): 485-492 (2018)

[49] Zhang J, Chen X C, Xu Q, Ma T B, Hu Y Z, Wang H, Tieu A $\mathrm{K}$, Luo J B. Effects of grain boundary on wear of graphene at the nanoscale: A molecular dynamics study. Carbon 143: 578-586 (2019)

[50] Li J J, Li J F, Chen X C, Liu Y H, Luo J B. Microscale superlubricity at multiple gold-graphite heterointerfaces under ambient conditions. Carbon 161: 827-833 (2020)

[51] Klein J, Kumacheva E, Mahalu D, Perahia D, Fetters L J. Reduction of frictional forces between solid surfaces bearing polymer brushes. Nature 370(6491): 634-636 (1994)

[52] Li J J, Zhang C H, Luo J B. Superlubricity behavior with phosphoric acid-water network induced by rubbing. Langmuir 27(15): 9413-9417 (2011)

[53] Ge X Y, Halmans T, Li J J, Luo J B. Molecular behaviors in thin film lubrication-Part three: Superlubricity attained by polar and nonpolar molecules. Friction 7(6): 625-636 (2019)

[54] Han T Y, Zhang C H, Li J J, Yuan S H, Chen X C, Zhang J Y, Luo J B. Origins of superlubricity promoted by hydrated multivalent ions. J Phys Chem Lett 11(1): 184-190 (2020)

[55] Meng Y G, Xu J, Jin Z M, Prakash B, Hu Y Z. A review of recent advances in tribology. Friction 8(2): 221-300 (2020) 
[56] Gray J. Studies in animal locomotion: VI. The propulsive powers of the dolphin. J Exp Biol 13(2): 192-199 (1936)

[57] Kramer Dr M O. Boundary layer stabilization by distributed damping. Nav Eng J 74(2): 341-348 (1962)

[58] Videler J J, Haydar D, Snoek R, Hoving H J T, Szabo B G. Lubricating the swordfish head. J Exp Biol 219(13): 1953-1956 (2016)

[59] Wen L, Weaver J C, Lauder G V. Biomimetic shark skin: Design, fabrication and hydrodynamic function. $J$ Exp Biol 217(10): 1656-1666 (2014)

[60] Walsh M J, Weinstein L M. Drag and heat transfer on surfaces with small longitudinal fins. In Proceedings of the 11th Fluid and Plasma Dynamics Conference, Seattle, USA, 1978: 1161.

[61] Walsh M, Lindemann A. Optimization and application of riblets for turbulent drag reduction. In Proceedings of the AIAA 22nd Aerospace Sciences Meeting, Reno, USA, 1984: 347.

[62] Bechert D W, Bruse M, Hage W, Van Der Hoeven J G T, Hoppe G. Experiments on drag-reducing surfaces and their optimization with an adjustable geometry. $J$ Fluid Mech 338: 59-87 (1997)

[63] García-Mayoral R, Jiménez J. Drag reduction by riblets. Phil Trans R Soc A 369(1940): 1412-1427 (2011)

[64] McClure P D, Smith B, Baker W, Yagle P. Design, testing and analysis of 2-D and 3-D riblets. In Proceedings of the AIAA Scitech 2020 Forum, Orlando, USA, 2020: 311

[65] Ran W, Zare A, Jovanović M R. Model-based design of riblets for turbulent drag reduction. J Fluid Mech 906: A7 (2021)

[66] García-Mayoral R, Jiménez J. Hydrodynamic stability and breakdown of the viscous regime over riblets. J Fluid Mech 678: 317-347 (2011)

[67] Bechert D W, Hoppe G, Reif W E. On the drag reduction of the shark skin. In Proceedings of the AlAA 23rd Aerospace Sciences Meeting, Reno, USA, 1985: 546-563.

[68] Park S R, Wallace J M. Flow alteration and drag reduction by riblets in a turbulent boundary layer. AIAA $J$ 32(1): 31-38 (1994)

[69] Quintavalla S J, Angilella A J, Smits A J. Drag reduction on grooved cylinders in the critical Reynolds number regime. Exp Therm Fluid Sci 48: 15-18 (2013)

[70] Daeian M A, Moosavi A, Nouri-Borujerdi A, Taghvaei E. Drag reduction in a channel with microstructure grooves using the lattice Boltzmann method. J Phys D Appl Phys 50(10): 105301 (2017)

[71] Lee C, Lee G W, Choi W, Yoo C H, Chun B, Lee J S, Lee J H, Jung H W. Pattern flow dynamics over rectangular Sharklet patterned membrane surfaces. Appl Surf Sci 514: 145961 (2020)
[72] Chien H W, Chen X Y, Tsai W P, Lee M. Inhibition of biofilm formation by rough shark skin-patterned surfaces. Colloids Surf B Biointerf 186: 110738 (2020)

[73] Zhao D Y, Huang Z P, Wang M J, Wang T, Jin Y F. Vacuum casting replication of micro-riblets on shark skin for dragreducing applications. J Mater Process Tech 212(1): 198-202 (2012)

[74] Schumacher J F, Carman M L, Estes T G, Feinberg A W, Wilson L H, Callow M E, Callow J A, Finlay J A, Brennan A B. Engineered antifouling microtopographies-effect of feature size, geometry, and roughness on settlement of zoospores of the green alga Ulva. Biofouling 23(1): 55-62 (2007)

[75] Martínez-Calderon M, Rodríguez A, Dias-Ponte A, Morant-Miñana M C, Gómez-Aranzadi M, Olaizola S M. Femtosecond laser fabrication of highly hydrophobic stainless steel surface with hierarchical structures fabricated by combining ordered microstructures and LIPSS. Appl Surf Sci 374: 81-89 (2016)

[76] Lee H, Lee B P, Messersmith P B. A reversible wet/dry adhesive inspired by mussels and geckos. Nature 448(7151): 338-341 (2007)

[77] Büttner C C, Schulz U. Shark skin inspired riblet coatings for aerodynamically optimized high temperature applications in aeroengines. Adv Eng Mater 13(4): 288-295 (2011)

[78] Schlieter A, Shakhverdova I, Leyens C. Fabrication of riblet structures on a Ni-based superalloy (PWA1483) for potential drag reduction in high temperature applications based on laser optimization. Adv Eng Mater 17(7): 1008-1016 (2015)

[79] Oehlert K, Seume J R, Siegel F, Ostendorf A, Wang B, Denkena B, Vynnyk T, Reithmeier E, Hage W, Knobloch K, et al. Exploratory experiments on machined riblets for 2-D compressor blades. In Proceedings of the ASME 2007 International Mechanical Engineering Congress and Exposition, Seattle, USA, 2007: 25-39.

[80] Li Y R, Mao H C, Hu P, Hermes M, Lim H, Yoon J, Luhar $\mathrm{M}$, Chen Y, Wu W. Bioinspired functional surfaces enabled by multiscale stereolithography. Adv Mater Technol 4(5): 1800638 (2019)

[81] Li F, Du M, Zheng Q. Dopamine/silica nanoparticle assembled, microscale porous structure for versatile superamphiphobic coating. ACS Nano 10(2): 2910-2921 (2016)

[82] Chen A F, Huang H X. Rapid fabrication of T-shaped micropillars on polypropylene surfaces with robust CassieBaxter state for quantitative droplet collection. J Phys Chem C 120(3): 1556-1561 (2016) 
[83] Bechert D W, Bruse M, Hage W, Meyer R. Fluid mechanics of biological surfaces and their technological application. Naturwissenschaften 87(4): 157-171 (2000)

[84] Bixlera G D, Bhushan B. Bioinspired micro/nanostructured surfaces for oil drag reduction in closed channel flow. Soft Matter 9(5): 1620-1635 (2013)

[85] Choi H, Moin P, Kim J. Direct numerical simulation of turbulent flow over riblets. J Fluid Mech 255: 503-539 (1993)

[86] Fu Y F, Yuan C Q, Bai X Q. Marine drag reduction of shark skin inspired riblet surfaces. Biosurf Biotribol 3(1): 11-24 (2017)

[87] Neinhuis C, Barthlott W. Characterization and distribution of water-repellent, self-cleaning plant surfaces. Ann Bot 79(6): 667-677 (1997)

[88] Barthlott W, Neinhuis C. Purity of the sacred lotus, or escape from contamination in biological surfaces. Planta 202: 1-8 (1997)

[89] Latthe S S, Terashima C, Nakata K, Sakai M, Fujishima A. Development of sol-gel processed semi-transparent and self-cleaning superhydrophobic coatings. J Mater Chem A 2(15): 5548-5553 (2014)

[90] Sun K, Yang H, Xue W, He A, Zhu D H, Liu W W, Adeyemi K, Cao Y. Anti-biofouling superhydrophobic surface fabricated by picosecond laser texturing of stainless steel. Appl Surf Sci 436: 263-267 (2018)

[91] Cao L L, Jones A K, Sikka V K, Wu J Z, Gao D. Anti-icing superhydrophobic coatings. Langmuir 25(21): 12444-12448 (2009)

[92] Zhang X, Huang Y L, Ma Z S, Niu L Y, Sun C Q. From ice superlubricity to quantum friction: Electronic repulsivity and phononic elasticity. Friction 3(4): 294-319 (2015)

[93] Zhang L H, Xu L D, Sun Y L, Yang N. Robust and durable superhydrophobic polyurethane sponge for oil/water separation. Ind Eng Chem Res 55(43): 11260-11268 (2016)

[94] Watanabe K, Udagawa Y, Udagawa H. Drag reduction of Newtonian fluid in a circular pipe with a highly waterrepellent wall. J Fluid Mech 381: 225-238 (1999)

[95] Ou J, Perot B, Rothstein J P. Laminar drag reduction in microchannels using ultrahydrophobic surfaces. Phys Fluids 16(12): 4635-4643 (2004)

[96] Joseph P, Cottin-Bizonne C, Benoit J M, Ybert C, Journet C, Tabeling P, Bocquet L. Slippage of water past superhydrophobic carbon nanotube forests in microchannels. Phys Rev Lett 97(15): 156104 (2006)

[97] Choi C H, Kim C J. Large slip of aqueous liquid flow over a nanoengineered superhydrophobic surface. Phys Rev Lett 96(6): 066001 (2006)

[98] Park H, Sun G Y, Kim C J C. Superhydrophobic turbulent drag reduction as a function of surface grating parameters. J Fluid Mech 747: 722-734 (2014)

[99] Srinivasan S, Kleingartner J A, Gilbert J B, Cohen R E, Milne A J, McKinley G H. Sustainable drag reduction in turbulent Taylor-Couette flows by depositing sprayable superhydrophobic surfaces. Phys Rev Lett 114(1): 014501 (2015)

[100] Tuo Y J, Zhang H F, Rong W T, Jiang S Y, Chen W P, Liu $\mathrm{X}$ W. Drag reduction of anisotropic superhydrophobic surfaces prepared by laser etching. Langmuir 35(34): 11016-11022 (2019)

[101] Erbil H Y, Cansoy C E. Range of applicability of the Wenzel and Cassie-Baxter equations for superhydrophobic surfaces. Langmuir 25(24): 14135-14145 (2009)

[102] Wenzel R N. Surface roughness and contact angle. J Phys Chem 53(9): 1466-1467 (1949)

[103] Cassie A B D, Baxter S. Wettability of porous surfaces. Trans Faraday Soc 40(1): 546-551 (1944)

[104] Feng Y, Zhang Y N, Xi J M, Zhu Y, Wang N, Xia F, Jiang L. Petal effect: A superhydrophobic state with high adhesive force. Langmuir 24(8): 4114-4119 (2008)

[105] Bhushan B, Her E K. Fabrication of superhydrophobic surfaces with high and low adhesion inspired from rose petal. Langmuir 26(11): 8207-8217 (2010)

[106] Wang J D, Liu F B, Chen H S, Chen D R. Superhydrophobic behavior achieved from hydrophilic surfaces. Appl Phys Lett 95(8): 084104 (2009)

[107] Ahmmed K M T, Patience C, Kietzig A M. Internal and external flow over laser-textured superhydrophobic polytetrafluoroethylene (PTFE). ACS Appl Mater Inter 8(40): 27411-27419 (2016)

[108] Wang Y, Yang J, Guo X B, Zhang Q, Wang J Y, Ding J N, Yuan N Y. Fabrication and tribological properties of superhydrophobic nickel films with positive and negative biomimetic microtextures. Friction 2(3): 287-294 (2014)

[109] Liu Y B, Liu J, Tian Y, Zhang H, Wang R M, Zhang B L, Zhang H P, Zhang Q Y. Robust organic-inorganic composite films with multifunctional properties of superhydrophobicity, self-healing, and drag reduction. Ind Eng Chem Res 58(11): 4468-4478 (2019)

[110] Cheng M J, Zhang S S, Dong H Y, Han S H, Wei H, Shi F. Improving the durability of a drag-reducing nanocoating by enhancing its mechanical stability. ACS Appl Mater Inter 7(7): 4275-4282 (2015)

[111] Truesdell R, Mammoli A, Vorobieff P, Van Swol F, Brinker C J. Drag reduction on a patterned superhydrophobic surface. Phys Rev Lett 97(4): 044504 (2006)

[112] Choi C H, Ulmanella U, Kim J, Ho C M, Kim C J. Effective slip and friction reduction in nanograted superhydrophobic 
microchannels. Phys Fluids 18(8): 087105 (2006)

[113] Shi F, Niu J, Liu J, Liu F, Wang Z, Feng X Q, Zhang X. Towards understanding why a superhydrophobic coating is needed by water striders. Adv Mater 19(17): 2257-2261 (2007)

[114] Ybert C, Barentin C, Cottin-Bizonne C, Joseph P, Bocquet L. Achieving large slip with superhydrophobic surfaces: Scaling laws for generic geometries. Phys Fluids 19(12): 123601 (2007)

[115] Neto C, Evans D R, Bonaccurso E, Butt H J, Craig V S J. Boundary slip in Newtonian liquids: A review of experimental studies. Rep Prog Phys 68(12): 2859-2897 (2005)

[116] Zheng K Q, Zhang J D, Dodiuk H, Kenig S, Barry C, Sun H W, Mead J. Effect of superhydrophobic composite coatings on drag reduction in laminar flow. ACS Appl Polym Mater 2(4): 1614-1622 (2020)

[117] Dong H Y, Cheng M J, Zhang Y J, Wei H, Shi F. Extraordinary drag-reducing effect of a superhydrophobic coating on a macroscopic model ship at high speed. J Mater Chem A 1(19): 5886-5891 (2013)

[118] Bocquet L, Lauga E. A smooth future? Nat Mater 10(5): 334-337 (2011)

[119] Xu M C, Sun G Y, Kim C J. Infinite lifetime of underwater superhydrophobic states. Phys Rev Lett 113(13): 136103 (2014)

[120] Lee C, Kim C J. Underwater restoration and retention of gases on superhydrophobic surfaces for drag reduction. Phys Rev Lett 106(1): 014502 (2011)

[121] Panchanathan D, Rajappan A, Varanasi K K, McKinley G H. Plastron regeneration on submerged superhydrophobic surfaces using in situ gas generation by chemical reaction. ACS Appl Mater Inter 10(39): 33684-33692 (2018)

[122] Aljallis E, Sarshar M A, Datla R, Sikka V, Jones A, Choi $\mathrm{C}$ H. Experimental study of skin friction drag reduction on superhydrophobic flat plates in high Reynolds number boundary layer flow. Phys Fluids 25(2): 025103 (2013)

[123] Shirtcliffe N J, McHale G, Newton M I, Zhang Y. Superhydrophobic copper tubes with possible flow enhancement and drag reduction. ACS Appl Mater Inter 1(6): 1316-1323 (2009)

[124] Spurk J H. On the gas loss from ventilated supercavities. Acta Mech 155(3): 125-135 (2002)

[125] Kawakami E, Arndt R E A. Investigation of the behavior of ventilated supercavities. J Fluid Eng 133(9): 091305 (2011)

[126] Paik B G, Park I R, Kim K S, Lee K, Kim M J, Kim K Y. Design of a bubble collecting section in a high speed water tunnel for ventilated supercavitation experiments. $J$
Mech Sci Technol 31(9): 4227-4235 (2017)

[127] Shafaghat R, Hosseinalipour S M, Derakhshani S M E. Derivation of a correlation for drag coefficient in twodimensional bounded supercavitating flows, using artificial neural networks. Arch Appl Mech 80(7): 771-784 (2010)

[128] Karn A, Arndt R E A, Hong J R. Dependence of supercavity closure upon flow unsteadiness. Exp Therm Fluid Sci 68: 493-498 (2015)

[129] Meng Q C, Zhang Z H, Liu J B. Numerical calculation of supercavitating flows over the disk cavitator of a subsonic underwater projectile. J Marine Sci Appl 14(3): 283-289 (2015)

[130] Gagool M, Przyjazny A, Boczkaj G. Wastewater treatment by means of advanced oxidation processes based on cavitation-A review. Chem Eng J 338: 599-627 (2018)

[131] Singhal A K, Athavale M M, Li H Y, Jiang Y. Mathematical basis and validation of the full cavitation model. J Fluid Eng 124(3): 617-624 (2002)

[132] Gevari M T, Abbasiasl T, Niazi S, Ghorbani M, Koşar A. Direct and indirect thermal applications of hydrodynamic and acoustic cavitation: A review. Appl Therm Eng 171: 115065 (2020)

[133] Gong B Z, Zhang B J, Zhang H. NEMD study for supercavitation mechanism with underwater object. Phys Lett A 372(47): 7063-7067 (2008)

[134] Dzielski J E. Longitudinal stability of a supercavitating vehicle. IEEE J Oceanic Eng 36(4): 562-570 (2011)

[135] Jiang C X, Li F C. Numerical study of natural supercavitation influenced by rheological properties of turbulent dragreducing additives. Adv Mech Eng 6: 275316 (2014)

[136] Cameron P J K, Rogers P H, Doane J W, Gifford D H. An experiment for the study of free-flying supercavitating projectiles. J Fluid Eng 133(2): 021303 (2011)

[137] Spurk J H. Effect of gas temperature on the gas loss from ventilated cavities. Acta Mech 172(1): 75-81 (2004)

[138] Zhang X W, Wei Y J, Zhang J Z, Wang C, Yu K P. Experimental research on the shape characters of natural and ventilated supercavitation. J Hydrodyn 19(5): 564-571 (2007)

[139] Vanek B, Bokor J, Balas G J, Arndt R E A. Longitudinal motion control of a high-speed supercavitation vehicle. $J$ Vib Control 13(2): 159-184 (2007)

[140] Lv Y P, Xiong T H, Yi W J. Multistability in a simplified underwater supercavity system. Int J Bifurcat Chaos 27(8): 1750121 (2017)

[141] Kuklinski R, Henoch C, Castano J. Experimental study of ventilated cavities on dynamic test model. In Proceedings of the 4th International Symposium on Cavitation, California, USA, 2001: 1-8. 
[142] Lee Q Y, Xue L P, He Y S. Experimental study of ventilated supercavities with a dynamic pitching model. $J$ Hydrodyn 20(4): 456-460 (2008)

[143] Hrubes J D. High-speed imaging of supercavitating underwater projectiles. Exp Fluids 30(1): 57-64 (2001)

[144] Zhang B, Zhang Y W, Yuan X L. Effects of the profile of a supercavitating vehicle's front-end on supercavity generation. J Marine Sci Appl 8(4): 323-327 (2009)

[145] Wallner T. Supercavitation: A German status report. Naval Forces 24(5): 97-102 (2003)

[146] Vanek B, Bokor J, Balas G. High-speed supercavitation vehicle control. In Proceedings of the AIAA Guidance, Navigation, and Control Conference and Exhibit, Keystone, Colorado, 2006: 1-8.

[147] Willke H, Blumenthal N. Supercavitation-A challenge for future underwater weapon systems. Naval Forces 22(3): 50-53 (2001)

[148] Klein J, Raviv U, Perkin S, Kampf N, Chai L, Giasson S. Fluidity of water and of hydrated ions confined between solid surfaces to molecularly thin films. J Phys: Condens Matter 16(45): S5437-S5448 (2004)

[149] Raviv U, Giasson S, Kampf N, Gohy J F, Jérôme R, Klein J. Lubrication by charged polymers. Nature 425(6954): 163-165 (2003)

[150] Chen M, Briscoe W H, Armes S P, Klein J. Lubrication at physiological pressures by polyzwitterionic brushes. Science 323(5922): 1698-1701 (2009)

[151] Burger E D, Munk W R, Wahl H A. Flow increase in the Trans Alaska Pipeline through use of a polymeric dragreducing additive. J Petrol Technol 34(2): 377-386 (1982)

[152] Myska J, Mik V. Application of a drag reducing surfactant in the heating circuit. Energ Buildings 35(8): 813-819 (2003)

[153] Figueredo R C R, Sabadini E. Firefighting foam stability: The effect of the drag reducer poly(ethylene) oxide. Colloid Surface A Physicochem Eng Aspects 215(1-3): 77-86 (2003)

[154] El-azm M M A, Kassab S Z, Elshafie S A. Experimental and numerical study for turbulent flow drag reduction in district cooling systems. CFD Letters 6(3): 113-125 (2014)

[155] Al-Sarkhi A. Drag reduction with polymers in gas-liquid/ liquid-liquid flows in pipes: A literature review. J Nat Gas Sci Eng 2(1): 41-48 (2010)

[156] Marhefka J N, Marascalco P J, Chapman T M, Russell A J, Kameneva M V. Poly( $N$-vinylformamide)-A drag-reducing polymer for biomedical applications. Biomacromolecules 7(5): 1597-1603 (2006)

[157] Kim N J, Kim S, Lim S H, Chen K, Chun W. Measurement of drag reduction in polymer added turbulent flow. Int
Commun Heat Mass 36(10): 1014-1019 (2009)

[158] Al-Yaari M, Soleimani A, Abu-Sharkh B, Al-Mubaiyedh U, Al-Sarkhi A. Effect of drag reducing polymers on oil-water flow in a horizontal pipe. Int $J$ Multiphase Flow 35(6): 516-524 (2009)

[159] Virk P S. Drag reduction fundamentals. AIChE J 21(4): 625-656 (1975)

[160] Shao X M, Lin J Z, Wu T, Li Y L. Experimental research on drag reduction by polymer additives in a turbulent pipe flow. Can J Chem Eng 80(2): 293-298 (2002)

[161] Pereira A S, Soares E J. Polymer degradation of dilute solutions in turbulent drag reducing flows in a cylindrical double gap rheometer device. J Non-Newton Fluid 179-180: 9-22 (2012)

[162] Benzi R, Ching E S C, Horesh N, Procaccia I. Theory of concentration dependence in drag reduction by polymers and of the maximum drag reduction asymptote. Phys Rev Lett 92(7): 078302 (2004)

[163] Shanshool J, Al-Qamaje H M. Effect of molecular weight on turbulent drag reduction with polyisobutylene. In Proceedings of the 1st Regional Conference of Engineering Sciences NUCEJ Spatial ISSUE, Baghdad, Iraq, 2008: 52-59.

[164] Vanapalli S A, Islam M T, Solomon M J. Scission-induced bounds on maximum polymer drag reduction in turbulent flow. Phys Fluids 17(9): 095108 (2005)

[165] Jubran B A, Zurigat Y H, Goosen M F A. Drag reducing agents in multiphase flow pipelines: Recent trends and future needs. Petrol Sci Technol 23(11-12): 1403-1424 (2005)

[166] Nakken T, Tande M, Nyström B. Effects of molar mass, concentration and thermodynamic conditions on polymerinduced flow drag reduction. Eur Polym J 40(1): 181-186 (2004)

[167] Kim O K, Little R C, Patterson R L, Ting R T. Polymer structures and turbulent shear stability of drag reducing solutions. Nature 250(5465): 408-410 (1974)

[168] Soares E J. Review of mechanical degradation and de-aggregation of drag reducing polymers in turbulent flows. J Non-Newton Fluid 276: 104225 (2020)

[169] Nguyen T Q, Kausch H H. Kinetics of polymer degradation in transient elongational flow. Macromol Chem Phys 190(6): 1389-1406 (1989)

[170] Zhang K, Hyun G H, Jin H J. Mechanical degradation of water-soluble acrylamide copolymer under a turbulent flow: Effect of molecular weight and temperature. $J$ Ind Eng Chem 33: 156-161 (2016)

[171] Moussa T, Tiu C. Factors affecting polymer degradation in turbulent pipe flow. Chem Eng Sci 49(10): 1681-1692 (1994) 
[172] Brostow W. Drag reduction and mechanical degradation in polymer solutions in flow. Polymer 24(5): 631-638 (1983)

[173] Brostow W, Ertepinar H, Singh R P. Flow of dilute polymer solutions: chain conformations and degradation of drag reducers. Macromolecules 23(24): 5109-5118 (1990)

[174] Liberatore M W, Baik S, McHugh A J, Hanratty T J. Turbulent drag reduction of polyacrylamide solutions: Effect of degradation on molecular weight distribution. $J$ Non-Newton Fluid Mech 123(2-3): 175-183 (2004)

[175] Cox L R, Dunlop E H, North A M. Role of molecular aggregates in liquid drag reduction by polymers. Nature 249(5454): 243-245 (1974)

[176] Zhang X, Duan X L, Muzychka Y. Degradation of flow drag reduction with polymer additives-A new molecular view. J Mol Liq 292: 111360 (2019)

[177] Shanshool J, Jabbar M F A, Slaiman I N. The influence of mechanical effects on degradation of polyisobutylene as drag reducing agents. Pet Coal 53(3): 218-222 (2011)

[178] Berman N S. Evidence for molecular interactions in drag reduction in turbulent pipe flows. Polym Eng Sci 20(7): 451-455 (1980)

[179] Brostow W. Drag reduction in flow: Review of applications, mechanism and prediction. J Ind Eng Chem 14(4): 409-416 (2008)

[180] Lumley J L. Drag reduction by additives. Annu Rev Fluid Mech 1: 367-384 (1969)

[181] Lumley J L. Drag reduction in two phase and polymer flows. Phys Fluids 20(10): S64-S70 (1977)

[182] De Gennes P G. Introduction to Polymer Dynamics. New York, USA: Cambridge University Press, 1990.

[183] Rabin Y, Zielinska B J A. Scale-dependent enhancement and damping of vorticity disturbances by polymers in elongational flow. Phys Rev Lett 63(5): 512-515 (1989)

[184] Van Dama P H J, Wegdam G H, Van Der Elsken J. The structure of turbulence in a dilute polymer solution. $J$ Non-Newton Fluid Mech 53: 215-225 (1994)

[185] Den Toonder J M J, Hulsen M A, Kuiken G D C, Nieuwstadt F T M. Drag reduction by polymer additives in a turbulent pipe flow: numerical and laboratory experiments. J Fluid Mech 337: 193-231 (1997)

[186] Pu X, Li G J, Huang H L. Preparation, anti-biofouling and drag-reduction properties of a biomimetic shark skin surface. Biol Open 5(4): 389-396 (2016)

[187] Viswanath P R. Aircraft viscous drag reduction using riblets. Prog Aerosp Sci 38(6-7): 571-600 (2002)

[188] Aoki K, Muto K, Okanaga H. Aerodynamic characteristics and flow pattern of a golf ball with rotation. Procedia Eng 2(2): 2431-2436 (2010)
[189] Alam F, Steiner T, Chowdhury H, Moria H, Khan I, Aldawi F, Subic A. A study of golf ball aerodynamic drag. Procedia Eng 13: 226-231 (2011)

[190] Wang W, He Y Y, Zhao J, Mao J Y, Hu Y T, Luo J B. Optimization of groove texture profile to improve hydrodynamic lubrication performance: Theory and experiments. Friction 8(1): 83-94 (2020)

[191] Monfared M, Alidoostan M A, Saranjam B. Experimental study on the friction drag reduction of superhydrophobic surfaces in closed channel flow. J Appl Fluid Mech 12(1): 69-76 (2019)

[192] Bhambri P, Narain R, Fleck B A. Thermo-responsive polymers for drag reduction in turbulent Taylor-Couette flow. J Appl Polym Sci 133(46): 44191 (2016)

[193] Min T, Choi H, Yoo J Y. Maximum drag reduction in a turbulent channel flow by polymer additives. J Fluid Mech 492: 91-100 (2003)

[194] Li F C, Kawaguchi Y, Yu B, Wei J J, Hishida K. Experimental study of drag-reduction mechanism for a dilute surfactant solution flow. Int $J$ Heat Mass Tran 51(3-4): 835-843 (2008)

[195] Wei J J, Kawaguchi Y, Li F C, Yu B, Zakin J L, Hart D J, Zhang Y. Drag-reducing and heat transfer characteristics of a novel zwitterionic surfactant solution. Int J Heat Mass Tran 52(15-16): 3547-3554 (2009)

[196] Abdulbari H A, Yunus R M, Abdurahman N H, Charles A. Going against the flow-A review of non-additive means of drag reduction. J Ind Eng Chem 19(1): 27-36 (2013)

[197] Merkle C L, Deutsch S. Microbubble drag reduction. In Frontiers in Experimental Fluid Mechanics. Gad-el-Hak M, Ed. Berlin, Heidelberg: Springer, 1989: 291-335.

[198] Quadrio M. Drag reduction in turbulent boundary layers by in-plane wall motion. Phil Trans $R$ Soc $A$ 369(1940): 1428-1442 (2011)

[199] Xia Q J, Huang W X, Xu C X. Direct numerical simulation of turbulent boundary layer over a compliant wall. J Fluid Struct 71: 126-142 (2017)

[200] Cai S P, Jin G Y, Li D M, Yang L. Drag reduction effect of coupling flexible tubes with turbulent flow. J Hydrodyn 20(1): 96-100 (2008)

[201] Han T Y, Zhang C H, Li J J, Yuan S H, Chen X C, Zhang J Y, Luo J B. Origins of superlubricity promoted by hydrated multivalent ions. J Phys Chem Lett 11(1): 184-190 (2020)

[202] Saranadhi D, Chen D Y, Kleingartner J A, Srinivasan S, Cohen R E, McKinley G H. Sustained drag reduction in a turbulent flow using a low-temperature Leidenfrost surface. Sci Adv 2(10): e1600686 (2016) 


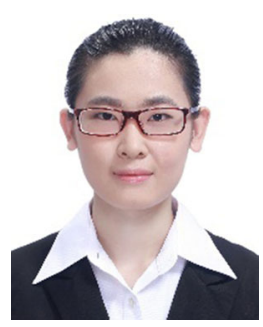

Min LIU. She obtained her bachelor degree in 2015 and master degree in 2018 from University of Science and Technology Beijing. Then, she become a Ph.D. candidate under

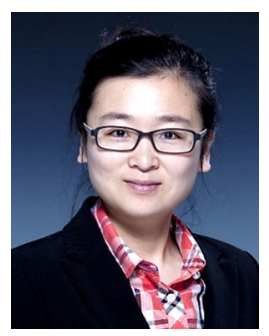

Liran MA. She received her Ph.D. degree in 2010 in Department of Precision Instrument and Mechanology from Tsinghua University (China). Following a postdoctoral period at the Weizmann Institute of Science in Israel, she is now the supervisor of Prof. Jianbin Luo at the State Key Laboratory of Tribology, Tsinghua University. Her research interests include superlubricity, solid-liquid interface behaviors, and drag reduction.

working as an associate professor in the State Key Laboratory of Tribology, Tsinghua University. She was elected as the Young Chang Jiang Scholar in 2015. Her current research interests are tribology and surface \& interface science. She has published over 60 SCI papers. 